See discussions, stats, and author profiles for this publication at: https://www.researchgate.net/publication/309558581

Systematics of the South American species of Cylindrostethus Mayr, 1865 (Hemiptera : Heteroptera : Gerridae), with a new species from Amazonian Brazil and Peru

Article in Invertebrate Biology · October 2016

DOI: $10.1071 /$ IS14059

CITATIONS

0

3 authors:

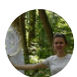

Carla Floriano

University of São Paulo

15 PUBlications 33 CITATIONS

SEE PROFILE

Rodney Ramiro Cavichioli

Universidade Federal do Paraná

144 PUBLICATIONS 463 CITATIONS

SEE PROFILE
READS

347

Andressa Paladini

Universidade Federal de Santa Maria

32 PUBLICATIONS 101 CITATIONS

SEE PROFILE

Some of the authors of this publication are also working on these related projects:

Phylogeny of Cercopidae (Hemiptera: Cicadomorpha) based on morphological data. View project 


\title{
Systematics of the South American species of Cylindrostethus Mayr, 1865 (Hemiptera : Heteroptera : Gerridae), with a new species from Amazonian Brazil and Peru
}

\author{
Carla Fernanda Burguez Floriano ${ }^{\mathrm{A}, \mathrm{B}, \mathrm{C}, \mathrm{E}}$, Andressa Paladini ${ }^{\mathrm{C}, \mathrm{D}}$ \\ and Rodney Ramiro Cavichioli ${ }^{\mathrm{C}}$ \\ ${ }^{A}$ Departamento de Ciências Biológicas, Universidade de São Paulo (USP), Ribeirão Preto, SP, Brazil. \\ ${ }^{B}$ Departamento de Ciências Biológicas, Universidade Estadual Paulista (UNESP), Assis, SP, Brazil. \\ ${ }^{\mathrm{C}}$ Departamento de Zoologia, Universidade Federal do Paraná (UFPR), Curitiba, PR, Brazil. \\ Departamento de Biodiversidade e Ecologia, Pontifícia Universidade Católica of Rio Grande do Sul, \\ Division of Biological Sciences, Porto Alegre, RS, Brazil. \\ ${ }^{\mathrm{E}}$ Corresponding author. Email: carlla.floriano@gmail.com
}

\begin{abstract}
Water striders (pond skaters) occur worldwide and are conspicuous in most aquatic environments, but the taxonomy of many groups remains unresolved. Here we revise the South American species of the Palaeo- and Neotropically distributed Cylindrostethus Mayr, 1865, a genus characterised by its long, cylindrical body and fast jumpinggliding locomotion. Using a cladistic analysis of morphological characters, we confirm the subdivision of Neotropical Cylindrostethus into two major groups. Nine species of Cylindrostethus are recognised from South America, one of which was recently discovered in Amazonian Brazil and Peru: C. bassleri Drake, 1952; C. bilobatus Kuitert, 1942; C. drakei, sp. nov.; C. hungerfordi Drake \& Harris, 1934; C. linearis (Erichson, 1848); C. meloi Floriano \& Cavichioli, 2013; C. palmaris Drake \& Harris, 1934; C. podargus Drake, 1958; C. regulus (White, 1879). Two species are placed in synonymy: $(C$. podargus $=C$. stygius Drake, 1961, syn. nov. $) ;(C$. linearis $=$ C. erythropus $($ Herrich-Schäffer, 1850), syn. nov.). A key to the nine species is provided, along with detailed descriptions and illustrations.
\end{abstract}

Additional keywords: Cylindrostethinae, Neotropical, taxonomy, water striders.

Received 27 November 2014, accepted 1 April 2016, published online 31 October 2016

\section{Introduction}

The family Gerridae Leach, 1815 currently comprises 75 genera and over 700 species of true bugs commonly called water striders or pond skaters (Polhemus and Polhemus 2008). The family is classified in eight subfamilies: Charmatometrinae, Cylindrostethinae, Eotrechinae, Gerrinae, Halobatinae, Ptilomerinae, Rhagadotarsinae and Trepobatinae (Andersen 1975; Damgaard et al. 2005; Polhemus and Polhemus 2008).

Cylindrostethinae includes three genera: Cylindrostethus Mayr, 1865 with 18 species from Neotropical, Oriental and Ethiopian regions (nine Neotropical, nine Palaeotropical) (Hungerford and Matsuda 1960); Potamobates Champion, 1898 with 19 species from the Neotropical region (Buzzetti 2006) from Peru to southern Mexico (Hungerford 1936; Polhemus and Polhemus 1995; Padilla-Gil and Damgaard 2011; MoralesCastaño et al. 2013); and Platygerris White, 1883 with three species occurring in Central America and northern South America (Hungerford and Matsuda 1960). According to Hungerford and Matsuda (1960), Cylindrostethinae is characterised by a short rostrum surpassing the prosternum; male proctiger usually with various degrees of asymmetry; apical margin of abdominal sternum VIII asymmetrical in species of Potamobates and Platygerris; meso- and metathoracic tarsal claws absent in all species occurring in the western hemisphere; antennomere IV short and curved distally; and apical margin of clypeus loosely connected with base of the labrum by a membranous region. Despite these apparent synapomorphies, a phylogenetic study combining morphological and molecular data (Damgaard 2008) did not support the monophyly of the subfamily.

Within the genus Cylindrostethus, species share the following features: body cylindrical and elongate, at least four times as long as wide; head strongly narrowed anteriorly and widened posteriorly; antennomere II longer than III; abdominal spiracles closer to the anterior margin of the segment; and male genitalia bilaterally symmetrical in South American species (Drake and Harris 1934; Kuitert 1942; Hungerford and Matsuda 1960). According to Hungerford and Matsuda (1960), Palaeotropical species of Cylindrostethus are characterised by the following features: proctiger rounded, with basolateral processes directed 
posteriorly; meso- and metathoracic femora as long as the maximum length of body, except in C. productus (Spinola, 1840) and $C$. costalis Schmidt, 1915; hind legs longer than length of body; anterior margin of mesosternum less pronounced; and presence of tarsal claws in meso- and metathoracic legs. On the other hand, the Neotropical species are characterised by having: basolateral processes of proctiger directed anteriorly; meso- and metathoracic femora distinctly shorter than maximum length of body; legs almost as long as body; anterior margin of mesosternum more pronounced; and meso- and metathoracic legs lacking tarsal claws.

To date, all known Neotropical species of Cylindrostethus are restricted to South America. Cylindrostethus palmaris has been found in all South American countries except Chile and Uruguay (Nieser 1970; Mazzucconi et al. 2008), whereas the remaining Neotropical species $-C$. bassleri Drake \& Harris, 1952; C. bilobatus Kuitert, 1942; C. erythropus (HerrichSchäffer, 1850); C. hungerfordi Drake \& Harris, 1934; C. linearis (Erichasin, 1848); C. meloi Floriano \& Cavichioli, 2013; C. podargus Drake, 1958; C. regulus (White, 1879); and C. stygius (Drake, 1961) - are known only from northern South America (Drake 1952; Nieser 1970; Moreira et al. 2011a, 2011b).

The lack of a robust phylogenetic hypothesis for Cylindrostethus reflects its systematics. Andersen (1982) suggested that Cylindrostethus might not be monophyletic given that Palaeotropical species have tarsal claws on the meso- and metathoracic legs whereas the Neotropical species do not.

Drake (1952) proposed two groups to accommodate the Neotropical species of Cylindrostethus. His Group 1 (C. bassleri, C. bilobatus, C. erythropus and C. linearis) is characterised by: a unicolorous mesonotum with longitudinal impressions; posterior margin of sternum VI deeply excavated in the middle; first genital segment broad, not tapering posteriorly, truncate apically; and upper lobe of second genital segment with a pair of long, divergent, prong-like processes at base, directed anterolaterally and downwards. Group 2 (C. hungerfordi, C. palmaris, C. regulus, C. podargus and C. stygius) is characterised by: the mesonotum with dark stripes on each side; the posterior margin of sternum VI with broad, rounded emargination in males; the first genital segment tapering towards the apex, then abruptly narrowed into an acute tip; and upper lobe of second genital segment expanded sideways at base, forming a small, plate-like structure.

The only previous phylogenetic analysis of Cylindrostethus, conducted by Polhemus (1994), was based on morphological data and yielded two sister clades, each exclusively comprising either Neotropical or Palaeotropical representatives. However, the author adopted the ground-plan character approach such that the data matrix has the Neotropical species represented as a single terminal, i.e. Polhemus assumed monophyly of the Neotropical Cylindrostethus. According to Polhemus, the lineage including South American species is supported by two synapomorphies: the absence of claws in mesothoracic legs and the apex of the proctiger being elongate and acute. In order to test the monophyly of the Palaearctic and Neotropical lineages, it will be important to sample all species for a comprehensive character list.
Ecological and biological data on species of Cylindrostethus are scarce. In Brazil, some authors observed a few species in streams, rivers and ponds (Moreira et al. 2011a), usually in shaded habitats (Nieser and Melo 1997). They can be found in association with macrophytes, floating litter banks and exposed roots (Pereira et al. 2007). Roback (1966), in his expedition to the Peruvian Amazon, reported the curious behaviour of specimens of $C$. erythropus that were on trunks near water bodies and which jumped in any direction when disturbed.

All species belonging to Cylindrostethus have a conspicuous behaviour when moving on the water surface, characterised by a strong push with the meso- and metathoracic legs followed by a long glide alternating between jumps and glides along a straight line. Species of other genera in the family are not as efficient when sliding at great speed over the water (Polhemus 1994).

Taxonomic studies of the South American species of Cylindrostethus are also scarce and are mostly represented by descriptions of new species. The main goals of this paper are:

(1) to provide a revision of $C y$ lindrostethus with an identification key to all valid species; and

(2) to present a phylogenetic hypothesis for the South American species of Cylindrostethus and to evaluate the speciesgroups proposed by Drake (1952).

\section{Materials and methods}

Specimens were borrowed from several Brazilian and international institutions, here listed in alphabetical order of the abbreviation: AMNH, American Museum of Natural History, New York, United States of America; BMNH, Natural History Museum, London, United Kingdom; DZRJ, Coleção Entomológica Prof. José Alfredo Pinheiro Dutra, Rio de Janeiro, Brazil; DZUP, Coleção Entomológica Padre Jesus Santiago Moure, Curitiba, Brazil; INPA, Coleção de Invertebrados do Instituto Nacional de Pesquisa da Amazônia, Manaus, Brazil; SEMC, Snow Entomological Collection, University of Kansas, Lawrence, United States of America; LACM, Natural History Museum of Los Angeles County, Los Angeles, United States of America; MPEG, Museu Paraense Emilio Goeldi, Belém, Brazil; UEMS, Coleção Entomológica da Universidade Estadual do Mato Grosso do Sul, Mundo Novo, Brazil; UPTC, Museo de Historia Natural Luis Gonzalo Andrade, Tunja, Colombia; USNM, National Museum of Natural History, Smithsonian Institution, Washington D.C., United States of America; ZSMC, Zoologisches Staatssammlung, Munich, Germany.

Label data are given inside quotation marks, with a reversed slash $(\backslash)$ and separating lines on the labels.

Specimens were examined and illustrated using a Zeiss dissecting microscope (SV 6, Jena, Thuringia, Germany) and Leica MZ 12.5 (Wetzlar, Hesse, Germany) and camera lucida. Phallus sclerites were illustrated with a camera lucida connected to an optical microscope (Wild M20, Gais, Appenzell Ausserrhoden, Switzerland). Specimens were identified based on the examination of original descriptions, type specimens, photographs and keys provided by Drake and Harris (1934), Kuitert (1942) and Moreira et al. (2011a). Genitalia of males and 
females were detached, immersed in a solution of $10 \%$ potassium hydroxide and placed in a warm bath for $\sim 15 \mathrm{~min}$. Dissected structures were then washed with water, warmed up in a solution of 3\% hydrogen peroxide to clear structures and then washed in $50 \%$ alcohol to remove air bubbles. After examination, dissections were stored in vials with glycerin and attached to the same pin as the specimen. Type specimens were not dissected.

In this paper, the visible abdominal sternites are considered to represent sternites II-VII because the first abdominal sternite is reduced in individuals of all subfamilies except Rhagadotarsinae (Hungerford and Matsuda 1960; Andersen 1982).

Series of photographs were taken using a Leica camera attached to a dissecting microscope and combined into multifocal images using the Syncroscopy Auto-Montage software (High Wycombe, Buckinghamshire, England). Subsequently, stacked images and drawings were edited in Adobe Photoshop and Adobe Illustrator. Scanning electron microscope (SEM) images were obtained at the Centro de Microscopia Eletrônica da Universidade Federal do Paraná. Distribution records were retrieved from the literature and data from labels on specimens.

A data matrix (Table 1) of 34 morphological characters (23 external and 11 male/female genitalia; Table 2), including 29 binary and five multistate characters, was assembled using WinClada (Nixon 1999-2002). Non-applicable characters were coded as '-' and missing data were coded as '?'. Parsimony analyses were performed using TNT software (Goloboff et al. 2008) with all characters treated as unordered using two character-weighting schemes: equal weights and implied weights (Goloboff 1993), choosing values of K from three to seven. Tree searches were run using the implicit enumeration option, an exhaustive search function that computes all possible trees when taxon sampling includes fewer than 24 terminals. Clade support was calculated using Bremer support (i.e. decay index; Bremer 1994) and 100 bootstrap pseudoreplicates implemented in TNT under an equal-weighting scheme. Only unambiguous characters were optimised on the resulting cladogram

We used morphological characters to partition the study specimens into distinct phenotypes, with the most useful characters being the length of the connexival spines and the proctiger, the shape of the basolateral processes of the proctiger, phallus, and phallic sclerite and colouration. After completing a preliminary phylogenetic analysis using these phenotypes, those that were sympatric with their sister lineage were considered to be distinct species. If a phenotype was allopatric with its sister lineage, we then looked at geographic variation to determine whether it would be better to consider it a geographic variant or a distinct species.

\section{Results and discussion}

The phylogenetic analysis performed in this study yielded one most parsimonious cladogram (Fig. 1) of 43 steps, CI =97 and $\mathrm{RI}=98$. The genus Cylindrostethus is supported by four synapomorphies: the elongated body (character $1_{0}$ ), the acute connexival spines (character 191), the symmetrical male genitalia (character $21_{0}$ ) and the elongated phallus (character $30_{1}$ ). The two groups proposed by Drake (1952) were recovered in this morphology-based phylogenetic analysis.

Polhemus (1994) conducted a phylogenetic analysis of the Palaeotropical species of Cylindrostethus; however, he assumed that the Neotropical species were monophyletic, and treated them as a single terminal. The author concluded that Cylindrostethus was divided into two sister clades, represented by the Neotropical and Palaeotropical species, and the phylogenetic relationships were addressed only in the latter group. In order to make further progress into the systematics of Cylindrostethus, to test and corroborate the monophyly of the Palaearctic and Neotropical lineages, it is important to sample all the species including an adequate characters list. The topology obtained in this study corroborates Group 1 proposed by Drake (1952). This clade is supported by one synapomorphy, the presence of spinules on abdominal sternites (character 120), with low Bremer support (1). We suggest this clade to be named linearis-group, because C. linearis is the oldest described species in the group.

Five species are included in linearis-group: C. bassleri, C. bilobatus, C. linearis, C. meloi and C. drakei, sp. nov. The first three species were placed in Group 1 by Drake (1952), and C. erytrhopus is herein considered to be synonymous with $C$. linearis; $C$. drakei, sp. nov. and $C$. meloi, the latter included in this group by Floriano and Cavichioli (2013), are within the linearis-group in this phylogenetic analysis.

Table 1. Data matrix comprising 34 morphological characters for Cylindrostethus taxa and outgroups

(-) not applicable; (?) missing; (bold) outgroup; (*) polymorphic character

\begin{tabular}{|c|c|c|c|c|c|c|c|c|c|c|c|c|c|c|c|c|c|c|c|c|c|c|c|c|c|c|c|c|}
\hline \multirow[t]{2}{*}{ Taxa } & \multicolumn{8}{|c|}{0} & \multicolumn{7}{|c|}{1} & \multicolumn{9}{|c|}{2} & \multicolumn{4}{|c|}{3} \\
\hline & 1 & 2 & 34 & 45 & 6 & 7 & 8 & 9 & $\begin{array}{lll}0 & 1 & 2\end{array}$ & 23 & 4 & 5 & 67 & & 9 & 0 & 1 & 2 & & +5 & 6 & 7 & 8 & 9 & 0 & 1 & 2 & 34 \\
\hline P. sumaco & 1 & & 11 & & 1 & $\mathbf{0}$ & $\mathbf{0}$ & 1 & -0 & $1-$ & - & 1 & -1 & 11 & $\mathbf{0}$ & $\mathbf{0}$ & 1 & 1 & 1 & ? & ? & ? & ? & $?$ & 2 & $?$ & ? & ? - \\
\hline P. horvathi & 1 & 0 & 1 & 11 & 1 & $\mathbf{0}$ & $\mathbf{0}$ & 1 & -0 & $1-$ & -- & 1 & -1 & 11 & $\mathbf{0}$ & $\mathbf{0}$ & 1 & 0 & 1 & ? & ? & ? & ? & $?$ & 2 & $?$ & $?$ & ? - \\
\hline C. bassleri & 0 & 0 & - & 11 & 1 & 0 & 0 & 1 & -0 & $\begin{array}{ll}0 & 0\end{array}$ & 0 & 0 & 11 & 10 & 1 & 3 & 0 & 0 & 1 & ( & 2 & 1 & 1 & 0 & $?$ & $?$ & $?$ & 11 \\
\hline C. bilobatus & 0 & 0 & 1 & 11 & 1 & 1 & 0 & 1 & -0 & $\begin{array}{ll}0 & 0\end{array}$ & 1 & 1 & -1 & 10 & 1 & 3 & 0 & 0 & 1 & ( & 3 & 1 & 1 & 1 & $?$ & $?$ & $?$ & $\begin{array}{ll}0 & 1\end{array}$ \\
\hline C. hungerfordi & 0 & 0 & 0 & 00 & 0 & 0 & 1 & 0 & $\begin{array}{ll}0 & 1\end{array}$ & $1-$ & - - & 1 & -0 & - & -1 & 1 & 0 & 0 & 1 & 2 & 21 & 2 & 1 & 0 & 0 & 1 & 1 & $\begin{array}{ll}0 & 1\end{array}$ \\
\hline C. linearis & 0 & 0 & 1 & 11 & 1 & 0 & 0 & 1 & -0 & $\begin{array}{ll}0 & 0\end{array}$ & 0 & 0 & $\begin{array}{ll}0 & 1\end{array}$ & 10 & 1 & 3 & 0 & 0 & 1 & ( & 2 & 0 & 0 & 0 & 1 & 0 & 0 & 11 \\
\hline C. meloi & 0 & 0 & 1 & 11 & 1 & 0 & 0 & 1 & -0 & $\begin{array}{ll}0 & 0\end{array}$ & 0 & 0 & 11 & 10 & 1 & 3 & 0 & 0 & 1 & ( & 3 & 1 & 1 & 1 & 1 & 0 & 0 & 11 \\
\hline C. palmaris & 0 & 0 & 0 & $0 \quad 0$ & 0 & 0 & 1 & 0 & 11 & $* 1$ & $1-$ & 1 & -0 & $0-$ & -1 & 2 & 0 & 0 & 1 & & & 2 & 1 & 0 & 1 & 0 & 0 & $\begin{array}{ll}0 & 0\end{array}$ \\
\hline C. podargus & 0 & 1 & 1 & & 1 & 0 & 0 & 1 & -0 & * 1 & & 1 & -0 & $0-$ & -1 & 2 & 0 & 0 & 0 & & 0 & 2 & 1 & 2 & 1 & 0 & 0 & \\
\hline C. regulus & 0 & 0 & 0 & 00 & 0 & 0 & 1 & 0 & 11 & $1-$ & -- & 1 & -0 & $0-$ & -1 & 1 & 0 & 0 & 1 & ) & 1 & 2 & 1 & 0 & 0 & 0 & 1 & $\begin{array}{ll}0 & 1\end{array}$ \\
\hline C. drakei & 0 & 0 & 1 & 11 & 1 & 0 & & 1 & -0 & $\begin{array}{ll}0 & 0\end{array}$ & 0 & 0 & 11 & 10 & 1 & 3 & 0 & 0 & 1 & 1 & 2 & 0 & 0 & 0 & 1 & 0 & 0 & 11 \\
\hline
\end{tabular}


Table 2. Explanation of characters used in cladistics analysis

\begin{tabular}{|c|c|c|}
\hline Character & States & Statistics \\
\hline 1. Body shape & $\begin{array}{l}\text { (0) Elongated and cylindrical } \\
\text { (length superior } 4 \times \text { the width) } \\
\text { (Figs } 10-13 \text { ); (1) not elongated } \\
\text { and cylindrical (length inferior } \\
4 \times \text { the width). }\end{array}$ & $\begin{array}{l}\text { Length: } 1 \text { IC: } 100 \\
\text { RI: } 100\end{array}$ \\
\hline 2. Antennomere IV, shape & $\begin{array}{l}\text { (0) Cylindrical (Fig. 6A, B); (1) } \\
\text { flattened (Fig. 6C). }\end{array}$ & $\begin{array}{l}\text { Length: } 1 \text { CI: } 100 \\
\text { RI: } 100\end{array}$ \\
\hline $\begin{array}{l}\text { 3. Antennomere IV, } \\
\text { orientation }\end{array}$ & $\begin{array}{l}\text { (0) Straight (Fig. 6B, C); (1) curved } \\
\text { (Fig. 6A). }\end{array}$ & $\begin{array}{l}\text { Length: } 1 \text { CI: } 100 \\
\text { RI: } 100\end{array}$ \\
\hline
\end{tabular}

4. Vertex punctations

\section{Clypeus, pilosity}

6. Eyes, size of spines

7. Female, mesonotum, posterior region of dorsal margin

8. General colouration

9. Apterous, mesonotum and metanotum, black stripes

10. Mesonotum, width of black

11. Male, anterior region of the metacetabulum
(0) Present (Fig. 4D); (1) absent (Fig. 4C).

(0) Glabrous (Fig. 4B); (1) densely pilose (Fig. $4 A$ ).

(0) Robust/large (Fig. 4F); (1) minute (Fig. 4E).

(0) Not extended above the metanotum (Fig. 2G); (1) extended above the metanotum, forming a protuberance (Fig. $2 F$ ).

(0) Predominantly black (Figs $10 \mathrm{~A}$, $B, 12,13)$; (1) predominantly yellow (Figs $10 C-F, 11$ ).

(0) Present (Figs 10C, D, 11); (1) absent (Figs 10A, B, 12, 13).

(0) Narrow, $3 \times$ narrower than median yellow stripe (Fig. 11A, $B)$; (1) as wide as central yellow stripe (Figs $10 C, D, 11 C, D$ ).

(0) Without tuft of setae; (1) with tuft of setae (Fig. 2A).
Notes

The elongated cylindrical body (Drake and Harris 1934; Hungerford and Matsuda 1960; Hungerford and Matsuda 1962; Polhemus 1994) is a synapomorphy for Cylindrostethus.

The flat antennomere IV is an autapomorphic feature of C. podargus. Drake (1958) described the antennae in this group as 'fairly stout'. In some specimens, it shows a median longitudinal groove.

Hungerford and Matsuda (1960) suggested that the posterior curve of antennomere IV could be a putative synapomorphy of Cylindrostethinae. However, some species of Cylindrostethus (C. hungerfordi, C. palmaris, C. podargus and C. regulus) have a straight antennomere. Members of the subfamily Ptilomerinae also have a curved antennomere IV, varying from slightly to strongly curved (Andersen 1982). The studied specimens of C. bassleri lack the antennomere IV, so it was not possible to code the character in this case. The straight antennomere IV is a synapomorphic feature of the regulus-group. RI: 100

Length: 1 CI: 100 RI: 100

Length: 1 CI: 100 RI: 100

Length: 1 CI: 100 RI: 100

Length: $1 \mathrm{CI}: 100$ RI: 100

Length: 1 CI: 100 RI: 100

Length: 1 CI: 100 RI: 100

Length: 1 CI: 100 RI: 100
Length: $1 \mathrm{CI}: 100$

All species in the regulus-group (except C. podargus) have small punctations on the vertex, a synapomorphic character of this group. In other species, punctations are absent in the apical portion of the vertex.

The glabrous clypeus is a synapomorphic character of the regulus-group (except $C$. podargus). In other species of Cylindrostethus the clypeus is covered with setae.

The spiny ventral margin of eyes is a synapomorphy of the regulus-group. They are well visible when specimens are examined in lateral view. In other species of Cylindrostethus, these spines are inconspicuous, forming small elevations on the margin of the eyes.

The protuberant dorsal margin extending above the metanonum is only present in females of C. bilobatus. Kuitert (1942) used this character in female descriptions.

Species of Cylindrostethus are generally yellow or black. The yellow colouration is a synapomorphy of the regulus-group (except C.podargus), it may vary from lighter to darker yellow, but never black.

The black stripes in the regulus-group (except C. podargus) is a synapomorphic character. This feature has previously been used by Drake and Harris (1934), Drake (1952) and Kuitert (1942).

The narrow black stripes in the mesonotum (state 0 ) was observed in a single species, C. hungerfordi. In the description of this species, Drake and Harris (1934) used this character as a diagnostic feature. When the stripes are as wide as the median yellow stripe, they may exhibit slight variation in conspecific specimens. 
Table 2. (continued)

\begin{tabular}{lll}
\hline Character & States & Statistics \\
\hline $\begin{array}{l}\text { 12. Abdomen, sternites, } \\
\text { spinules }\end{array}$ & (0) Present; (1) absent. & Length: 1 CI: 100 \\
& & RI: 100
\end{tabular}

13. Abdomen, sternites, spinules, amount and distribution

14. Abdomen, sternites, location of spinules

15. Abdomen, sternites, central concavities

16. Abdomen, sternites V-VII, location of concavities

17. Abdomen, sternite VII, emarginate at middle

18. Abdomen, sternite VII, shape of median notch

19. Abdomen, connexival spines, shape

20. Abdomen, connexival spines, length
(0) Abundant and agglomerated;

(1) sparse and scattered.

Length: 1 CI: 100 IR: 100

(0) On the centro-posterior region; (1) on the posterior region.

Length: $1 \mathrm{CI}: 100$ RI: 100

Length: 1 CI: 100 RI: 100

Length: 1 CI:100 RI: 100

(1) only on sternite VII.

(0) Absent (margin rounded)

(Fig. 8A-D); (1) present

(emarginate at middle)

(Fig. $8 E-I$ ).

(0) Strongly marked (Fig. $8 E-I$ ); (1) subtle.

Length: 1 CI: 100 RI: 100

(0) Rounded; (1) acute (Figs 7, 8). Length: 1 CI: 100 RI: 100

Length: 3 CI: 100 RI: 100
Very short; (1) short, 3/10 the length of tergite VIII (Fig. $7 C$, $D$ ); (2) intermediate, $\sim 1 / 2$ the length of tergite VII (Fig. 7A, $B$ ); (3) long, $3 / 5$ the length of tergite VIII (Fig. 7E-I).
Notes

The spinules on the abdominal sternites of males are synapomorphic to the Neotropical species of Cylindrostethus. Old World Cylindrostethus have spinules on both abdominal and thoracic sternites. The absence of spinules is considered plesiomorphic for the genus. According to Polhemus (1994), the spinules first evolved in the abdomen, and later in the meso- and metathoracic sternites; in the same contribution, the author indicated that the absence of spinules was a synapomorphy of the Neotropical species. However, several Neotropical species have spinules on abdominal sternites, and this is a synapomorphic feature of the linearis-group. The spinules are also present in C. palmaris and C. podargus, but they are polymorphic in these species.

The spinules on abdominal sternites may be sparsely distributed (as in C. palmaris and C. podargus) or numerous and clumped together (a synapomorphic feature of the linearis-group).

Abdominal spinules are numerous and agglomerated in the linearis-group, and are located on the posterior region of sternites (as in C. bilobatus); alternatively, they can be located on the central region (as in C. bassleri, C. linearis, C. meloi and C. drakei, sp. nov.).

Species in the linearis-group (except for C. bilobatus) have concavities in the posterior region of abdominal sternites, a synapomorphic feature of C. meloi (C. meloi (C. bassleri (C. linearis C. drakei, sp. nov.))).

The concavities on sternites V-VII are an autapomorphic feature of C. linearis; in C. bassleri, C. meloi and C. drakei, sp. nov. the concavity is seen only in sternite VII.

Drake (1952) observed a conspicuous notch in sternite VII, and used it as a character to differentiate species in Group 1 from species in Group 2. This median notch is also found in two outgroup taxa (Potamobates horvathi Esaki, 1926 and Potamobates sumaco Cognato, 1998).

In the linearis-group, the median notch is strongly marked, whereas in $P$. sumaco and $P$. horvathi the median notch is much less conspicuous.

The conspicuous connexival spines is a synapomorphy of Cylindrostethus. When present, the spines in species of Potamobates are not acute (Hungerford and Matsuda 1960; Polhemus and Polhemus 1995; Polhemus 1994).

In Palaeotropical species, the connexival spines may be elongate (longer than the tergite VIII), and usually reach the apex of tergite VIII in Neotropical species. The progressive prolongation of the connexival spines is considered apomorphic (Polhemus 1994). These spines are long in the linearis-group, of intermediate length in C. palmaris and C. podargus and short in C. hungerfordi and C. regulus. 
Table 2. (continued)

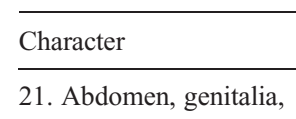
shape

\begin{tabular}{lc} 
States & Statistics \\
\hline (0) Bilaterally symmetrical & Length: 1 CI: 100 \\
(Figs 7-9); (1) asymmetrical. & RI: 100
\end{tabular}

RI: 100
22. Genitalia, orientation

23. Sternum VIII, shape of margins

24. Proctiger, length

25. Basolateral processes, length in relation to width

26. Basolateral processes, shape

\section{Proctiger, distance} between the apices of basolateral processes in relation to proctiger length

\section{Basolateral process, length}

29. Basolateral processes, shape of the apex

30. Phallus, shape

31. Phallic sclerite, shape
(0) Not rotated (Figs 7-9); (1) rotated.

(0) Constricted centrally (Fig. $8 A$ ); (1) straight (Fig. 8B-I).

(0) Long, with short basolateral processes (Fig. 9A-D); (1) short, with long basolateral processes (Fig. $9 E-G$ ).

(0) Elongate (Figs $8 E-I, 9 E-G$ ); (1) subequal (Figs $8 A-B, 9 A, B$ ); (2) $2 \times$ wider than long (Figs $8 C$, $D, 9 C, D)$.

(0) Rectangular (Figs 8A, 9A); (1) oval (Figs $8 B-D, 9 B-D$ ); (2) cylindrical (Figs $8 G-I, 9 F, G$ ); (3) triangular (Figs $8 E, F, 9 E$ ).

(0) Longer than proctiger (Figs $8 H$, $I, 9 F, G)$; (1) narrower than proctiger (Figs $8 E-G, 9 E$ ); (2) very narrow (Figs $8 A-D$, $9 A-D)$.

(0) Long, reaching the connexival spines (Fig. 8H,I); (1) short, not reaching the connexival spines (Fig. 8A-G).

(0) Rounded (Figs $8 B-D, G-I$, $99 B-D, F, G) ;(1)$ acute (Figs $8 E, F, 9 E)$; (2) truncate (Figs $8 A, 9 A$ ).

(0) Semicircular; (1) elongate.

(0) Semicircular (Fig. 2C); (1) distinctly expanded, apex emarginate medially (Fig. 2B).
Length: $1 \mathrm{CI}: 100$

RI: 100

Length: 1 IC: 100 IR: 100

Length: 1 CI: 100 RI: 100

Length: 2 CI: 100 RI: 100

Length: 3 CI: 100 RI: 100

Length: 2 CI: 100 RI: 100

Length: 1 CI: 100 RI: 100

Length: 3 CI: 66 RI: 0

Length: 2 CI: 100 RI: 100

Length: 1 CI: 100 RI: 100
Notes

The male genitalia is bilaterally symmetrical in the Neotropical species of Cylindrostethus, and asymmetrical in Palaeotropical species (Hungerford and Matsuda 1960; Hungerford and Matsuda 1962; Polhemus 1994). The bilaterally symmetrical proctiger is a plesiomorphic condition, and the asymmetry is a consequence the enlargement of the left basolateral process (Polhemus 1994). The genitalia in species of Potamobates exhibit asymmetric variations, like processes in the posterior margin of tergite VIII (Hungerford and Matsuda 1960; Polhemus \& Polhemus 1994;).

In Potamobates, the male genitalia is rotated counterclockwise, except in $P$. thomasi (Hungerford and Matsuda 1960; Polhemus 1994;).

The constricted sternum VIII is an autapomorphy of C. podargus; however, this feature may not be as conspicuous in some specimens; in such cases, the specimen needs to be slightly rotated to accurately observe the shape of the sternum.

Species in the linearis-group have a short proctiger with long basolateral processes, whereas species in the regulus-group have a long proctiger with short basolateral processes.

In Cylindrostethus, the proctiger has lateral expansions that show great variation (Polhemus 1994). For instance, in species of the linearis-group, the basolateral processes are longer than wide, in $C$. palmaris and $C$. podargus are nearly as long as wide and in C. hungerfordi and C. regulus are wider than long.

The cylindrical basolateral processes are a synapomorphic feature of (C. bassleri (C. linearis C. drakei, sp. nov.)). Cylindrostethus bilobatus and C. meloi have triangular basolateral processes, and only in C. podargus the process is rectangular. In the remaining species, the processes are oval.

The distance between the apices of basolateral processes apex greater than the length of proctiger is a synapomorphic feature of $C$. linearis $+C$. drakei, sp. nov. In C. bassleri, C. bilobatus and C. meloi, the distance is nearly equivalent to proctiger length. In the remaining species, the apices of basolateral processes are closer to each other.

The elongated basolateral process (reaching the connexival spines) is a synapomorphy of C. linearis $+C$. drakei, sp. nov.

In C. meloi and C. bilobatus, the apex of basolateral processes is acute; in C. podargus, the apex is truncate, and in the remaining species, the apex is rounded.

The elongate phallus was recovered as a synapomorphy of Cylindrostethus.

The emarginate apex is an autapomorphy of C. hungerfordi. 
Table 2. (continued)

\begin{tabular}{|c|c|c|c|}
\hline Character & States & Statistics & Notes \\
\hline $\begin{array}{l}\text { 32. Phallus, apex of } \\
\text { sclerite, length of the } \\
\text { projections }\end{array}$ & $\begin{array}{l}(0) \sim 2 \times \text { longer than the width of its } \\
\text { confluence area; }(1) \text { as long as } \\
\text { the width of its confluence area. }\end{array}$ & $\begin{array}{l}\text { Length: } 1 \text { CI: } 100 \\
\text { RI: } 100\end{array}$ & $\begin{array}{l}\text { The apical projections in the phallic sclerite as long as } \\
\text { the width of its confluence area are considered a } \\
\text { synapomorphic feature of the clade } \\
\text { C. hungerfordi }+ \text { C. regulus. }\end{array}$ \\
\hline 33. Tergite VIII, shape & (0) Elongate; (1) subquadrangular. & $\begin{array}{l}\text { Length: } 1 \text { CI: } 100 \\
\text { RI: } 100\end{array}$ & $\begin{array}{l}\text { The subquadrangular tergite VIII is a synapomorphy } \\
\text { of }(C \text {. meloi (C. bassleri (C. linearis C. drakei, sp. } \\
\text { nov. ))). }\end{array}$ \\
\hline $\begin{array}{l}\text { 34. Apex of tergite VIII, } \\
\text { shape }\end{array}$ & $\begin{array}{l}\text { (0) Acute (Fig. 2E); (1) rounded } \\
\text { (Fig. 2D). }\end{array}$ & $\begin{array}{l}\text { Length: } 1 \text { CI: } 100 \\
\text { RI: } 100\end{array}$ & $\begin{array}{l}\text { The acute apex of tergite VIII is an autapomorphy of } \\
\text { C. palmaris. }\end{array}$ \\
\hline
\end{tabular}

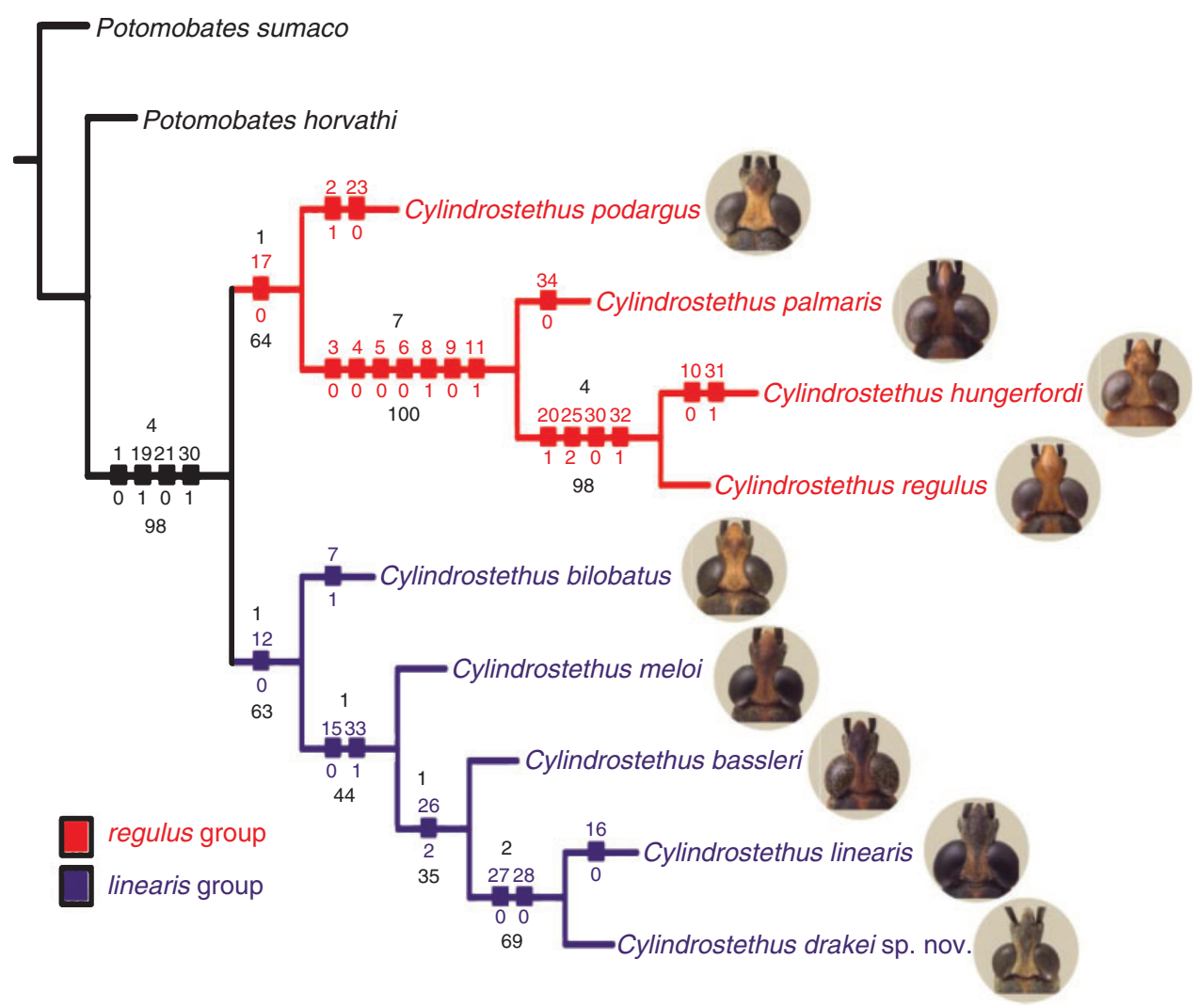

Fig. 1. Most parsimonious cladogram obtained with equally weighted characters. Relative Bremer support is indicated above each node. Bootstrap is indicated below each node.

The clade ( $C$. bilobatus (C. meloi ( $C$. bassleri ( $C$. linearis, C. drakei, sp. nov.)))) is supported by a single synapomorphy: sternites abdominal with spinules (character 12 $)$. The clade (C. meloi (C. bassleri (C. linearis, C. drakei, sp. nov.))) is supported by two synapomorphies: abdominal sternites with medial concavities (character $15_{0}$ ), and subquadrangular tergite VIII (character $33_{1}$ ). The clade (C. bassleri (C. linearis, $C$. drakei, sp. nov.)) is supported by a single synapomorphy: the cylindrical basolateral processes of proctiger (character $26_{2}$ ). Cylindrostethus linearis $+C$. drakei, sp. nov. share two synapomorphies: the distance between the apices of basolateral processes is greater than the length of the proctiger (character $27_{0}$ ), and the basolateral process reaches and overlaps the connexival spines (character 28, ).

Group 2 sensu Drake (1952) was also recovered as monophyletic, but with low Bremer support (1). This clade is supported by a single synapomorphy: apex of sternite VII rounded in males (character 170). We suggest this clade to be named the regulus-group, because $C$. regulus is the oldest described species included in the group. It consists of (C. podargus (C. palmaris (C. hungerfordi, C. regulus $))$ ). The clade comprising $C$. hungerford $i+C$. regulus is well supported 
$($ Bremer $=4)$ by four synapomorphies: short connexival spines $\left(20_{1}\right)$; the shape of the basolateral processes (wider than long) $\left(25_{2}\right)$; semicircular phallus $\left(30_{0}\right)$; and apical projection of sclerite as long as its confluence area $\left(32_{1}\right)$.

According to Polhemus (1994), Cylindrostethus species are similar in their external morphology, differing primarily in small details of the male and female genital and pregenital structures. Comparing South American species of Cylindrostethus with species of other genera of Cylindrostethinae (e.g. Platygerris and Potamobates), we can affirm that the former show less intra- and interspecific variation. However, even the small morphological variation of the South American Cylindrostethus clade allows us to define characters and to resolve its internal relationships.

\section{Taxonomy}

\section{Cylindrostethus Mayr, 1865}

Type species: Cylindrostethus productus (Spinola, 1840) (= Cylindrostethus fieberi Mayr, 1865) by monotypy.

Cylindrostethus Fieber, 1861: 33.[(gen. nov.: nom. nud.; key to genus]. Mayr, 1865: 444. [redescription of genus, description of first species, C. fieberi $=$ Gerris productus Spinola, 1840]. Drake \& Harris, 1934: 218, 238-239 [redescription, key to species, illustration]. Kuitert, 1942: 135 [redescription, key to species]; Drake, 1952: 3 (new speciesgroups). Hungerford \& Matsuda, 1960: 224-227, 504-509 [redescription, illustration]. Hungerford \& Matsuda, 1962: 83-84, 103-111 [taxonomic remarks]. Polhemus, 1994: 3-6, 26 -27 [redescription, key, illustration]; Aristizábal, 2002: 81 [key, illustration].

Hydrobates Erichson, 1848: 614 [gen. nov.; name preoccupied by Hydrobates Boie, 1822 in Aves].

When erecting Cylindrostethus, Fieber (1861) did not include any species. The International Code of Zoological Nomenclature (Article 12.2) states that nominal genera described before 1931 must include one or more available nominal species, which should be clearly stated in the description (ICZN 2000). For this reason, the name Cylindrostethus Fieber, 1861 was unavailable (nomen nudum) until Mayr (1865) described a new species in the genus, $C$. fieberi. Although the genus authorship is sometimes attributed to Fieber (1861), Mayr is the authority of Cylindrostethus, the publication date is 1865 and C. fieberi Mayr, 1865 is the type species by monotypy.

The genus redescription below refers only to the South American species.

\section{Diagnosis}

Body cylindrical and elongate, six times as long as wide (Figs 10-13); maxillary and mandibular plates fused, rostrum short, not reaching the mesosternum (Figs 3A, 15); usually apterous (except for $C$. palmaris); meso- and metathoracic tarsal claws absent (Fig. $3 A, B$ ); connexival spines shorter than the length of tergite VIII (Fig. 7); proctiger bilaterally symmetrical, basolateral processes directed laterally or anteriorly (Figs 8, 9).

\section{Redescription}

Male and female: apterous except for $C$. palmaris. Body cylindrical and elongate (Figs 10-13). Head: with median length $2 / 3$ shorter than transocular distance, in dorsal view; lateral margins of vertex diverging anteriorly and posteriorly, C-shaped; antennal tubercles projecting and divergent, in dorsal view; eyes oval and protuberant, $1-2 \times$ as large as interocular width (Fig. 14); antennae smaller than prothoracic legs; antennomere I longer than II and III combined; antennomere III approximately half as long as IV; clypeus rounded anteriorly, basal margin absent (Fig. 4A, B); mandibular and maxillary plates fused (Fig. $3 A$ ); rostrum short, not reaching the mesosternum (Figs 3A, 15), article III 1.4-2.5× longer than article IV. Thorax: pronotum $1 / 2-1 / 3$ as long as head width, posterolateral margins oblique, posterior margin slightly curved; mesonotum at least $1.4 \times$ as long as pronotum and metanotum combined; posterior margin slightly notched; metanotum subequal or slightly longer than pronotum. Prothoracic femora more robust than meso- and metathoracic femora, bearing spines on anterodorsal region; femora subequal or slightly longer than tibiae, tarsomere II 1.8-3.2 $\times$ longer than tarsomere I, subapical tarsal claws present. Mesothoracic legs longer than metathoracic legs, femora 1.5-1.8 $\times$ smaller than body length; mesothoracic tarsi flattened, longer than pro- and metathoracic tarsi, tarsomere I $\sim 3 \times$ longer than tarsomere II; meso- and metathoracic tarsal claws absent (Fig. 3B). Metathoracic femora $1.6 \times$ as long as tibia; tarsal claws absent (Fig. 3C). Abdomen: approximately as long as mesothoracic femora: lateral margins parallel, divergent or convergent; tergite I ovate or cordate, smaller than others; tergites II-IV rectangular, equal in size.

Male: connexival spines subequal to or shorter than length of tergite VIII (Fig. 7); proctiger bilaterally symmetrical, length variable (0.9-2.2 mm), apical margin acute, basolateral processes variable: short with rounded or truncate apex, or long with rounded or acute apex (Figs 8, 9); apex of pygophore rounded to nearly acute (Fig. 8). Female: connexival spines distinctly smaller than length of tergite VIII, gonocoxae with or without spines.

Colouration: varying from black to yellow, with black antennae and antennal tubercles (Figs 10-13).

\section{Comments}

This genus is easily distinguished from the other genera of Cylindrostethinae in having: body cylindrical and elongate, six times as long as wide (Figs 10-13), whereas in Potamobates and Platygerris the body length is less than four times the width; antennomere II longer than III, whereas in Potamobates and Platygerris antennomere II is equal to or smaller than III; abdominal spiracles closer to the anterior margin of the segment, whereas in Potamobates and Platygerris spiracle is located on the middle portion; Cylindrostethus has the proctiger bilaterally symmetrical with basolateral processes directed laterally or anteriorly (Figs 8, 9), whereas Potamobates and Platygerris have the basolateral process of proctiger directed cephalad and assymetrical. 
Species included in Cylindrostethus

Cylindrostethus bassleri Drake, 1952. Distribution: Peru (Amazonas)

Cylindrostethus bilobatus Kuitert, 1942. Distribution: Bolivia (Beni), Brazil (Mato Grosso*)

Cylindrostethus costalis Schmidt, 1915. Distribution: Indochina

Cylindrostethus drakei, sp. nov. Distribution: Brazil (Amazonas, Pará, Rondônia), Peru (Loreto)

Cylindrostethus hungerfordi Drake \& Harris, 1934. Distribution: Bolivia, Brazil (Amapá*, Pará), Guyana (East Berbice), Suriname (Brokopondo, Sipaliwini)

Cylindrostethus linearis (Erichson 1848). Distribution: Bolivia (Beni), Brazil (Amazonas, Pará, Roraima), Ecuador (Napo), Guyana, Peru (Loreto)

Cylindrostethus malayensis Polhemus, 1994. Distribution: Malay Peninsula below the Isthmus of Kra, and northern Sumatra

Cylindrostethus meloi Floriano \& Cavichioli, 2013. Distribution: Brazil (Amazonas)

Cylindrostethus palmaris Drake \& Harris, 1934. Distribution: Argentina, Bolivia (Beni), Brazil (Amapá, Amazonas, Bahia, Maranhão, Mato Grosso, Mato Grosso do Sul, Minas Gerais, Pará, Rio de Janeiro, Rio Grande do Norte, Rondônia, Roraima, São Paulo), Colombia (Caquetá, Casanare, Meta, Putumayo, Vaupés) Ecuador (Napo), French Guyana (Cayenne), Guyana (Demerara-Mahaica, East Berbice-Corentyne, Marowijne), Suriname (Brokopondo, Marowijne, Para, Sipaliwini), Trinidad \& Tobago (Diego Martín, San Juan-Laventille, Sangre Grande, Siparia, TunapunaPiarco), Venezuela (Amazonas, Aragua, Baritas, Monagas)

Cylindrostethus persephone Kirkady, 1899. Distribution: (Celebes)

Cylindrostethus podargus Drake, 1958. Distribution: Brazil* (Rondônia), Peru (Loreto)

Cylindrostethus productus (Spinola, 1840). Distribution: Ceylon Cylindrostethus quadrivittatus Bergroth, 1916. Distribution: (West Africa)

Cylindrostethus regulus (White, 1879). Distribution: Brazil (Amazonas,

Pará*), Colombia* (Putumayo), Peru* (Loreto)

Cylindrostethus samarinda Polhemus, 1994. Distribution: Borneo

Cylindrostethus scrutator (Kirkaldy, 1899). Distribution: Malaysia

Cylindrostethus sumatranus Lundblad, 1933. Distribution: Sumatra

Cylindrostethus vittipes (Stal, 1870). Distribution: Philippines.

* New records.

\section{Key to species of South American Cylindrostethus}

1. Wings well developed (Fig. 10E, F)..... ....................................... palmaris Drake \& Harris, 1934 (in part)

Wings not developed (apterous) (Figs $10 A-D, 11-13) \ldots \ldots \ldots \ldots \ldots \ldots \ldots \ldots \ldots . . . .22$

2. Antennomere IV straight (Fig. 6B) or flat and broad (Fig. 6C); male: apex of sternite VII not emarginate at middle (Fig. $8 A-D$ ); basolateral processes of proctiger distinctly shorter than wide, directed laterally (Fig. 9A-D)

Antennomere IV slightly curved (Fig. 6A); male: apex of VII sternite conspicuously excavated at middle (Fig. $8 E-I$ ); basolateral processes of proctiger $3 \times$ longer than wide, directed anteriorly (Fig. $9 E-G$ )......6

3. Mostly yellow (Figs $10 C-F, 11$ ); anterior portion of metacetabula with a tuft of setae (Fig. 2A) ........................................................................

Mostly black (Fig. 10A, B); anterior portion of metacetabula lacking a tuft of setae ................................................... . podargus Drake, 1958

4. Lateral black stripes of mesonotum $3 \times$ as narrow as central yellow stripe (Fig. 11A, B); male: base of phallic sclerite large and emarginate at middle (Fig. 2B) ........................... . hungerfordi Drake \& Harris, 1934

Lateral black stripes of mesonotum approximately as wide as central yellow stripe (Figs $10 C, D, 11 C, D$ ); male: base of phallic sclerite not enlarged at middle, round (not emarginate) (Fig. 2C).....
5. Body length $>20 \mathrm{~mm}$; prothoracic tibiae yellow with longitudinal black stripes; males: basolateral processes of proctiger $2 \times$ as wide as long (Fig. 9D); females: apex of tergite VIII rounded (Fig. 2D)..... C. regulus (White, 1879 )

Body length $\leq 20 \mathrm{~mm}$; prothoracic tibiae black; males: basolateral processes of proctiger $1-1.4 \times$ as wide as long (Fig. 9B); females: apex of the tergite VIII acute (Fig. 2E) ..

C. palmaris Drake \& Harris, 1934

6. Females: posterior margin of mesonotum projected over metanotum (Fig. $2 F$ ); males: basolateral processes of proctiger small, not visible in dorsal view (Fig. 7E); posterior region of sternites $\mathrm{V}$ and VI with minute spinules ............................................. C. bilobatus Kuitert, 1942

Females: apex of mesonotum with indistinct projection, not extended over metanotum (Fig. 2G); male: basolateral processes of proctiger long, visible in dorsal view (Fig. $7 F-I$ ); central region of sternites IV-VI with minute spinules.

7

7. Male: distance between apices of basolateral processes equal or slightly smaller than median length of proctiger (Fig. 9E); apices of basolateral processes of proctiger not concealed by connexival spines in dorsal

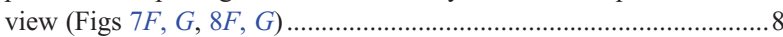

Male: distance between apices of basolateral processes larger than $1.2 \times$ the median length of proctiger (Fig. $9 F, G$ ), apices of basolateral processes of proctiger concealed by connexival spines in dorsal view (Figs $7 H, I, 8 H, I)$...

8. Male: basolateral processes of proctiger rounded apically (Figs $7 G, 8 G$ ) ..C. bassleri Drake, 1952

Male: basolateral processes of proctiger acute apically (Figs $7 F, 8 F, 9 E$ ) C. meloi Floriano \& Cavichioli, 2013

9. Mostly brown; male: lateral margins of abdomen slightly divergent posteriorly, tergite VII $1.2 \times$ as wide as tergite II; sternite VI depressed at lateral margins; basolateral processes slightly curved (Fig. $9 G$ ), strongly convergent, anterior width $\sim 3 / 10$ of posterior

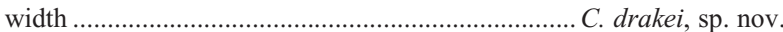

Mostly black or brown; male: lateral margins of abdomen strongly divergent posteriorly, tergite VII $1.3-1.5 \times$ as wide as tergite II; sternites IV-V and VII depressed at centre; basolateral processes not curved (Fig. 9F), not distinctly convergent, anterior width about half the posterior width C. linearis (Erichson, 1848)

\section{regulus-group}

\section{Diagnosis}

Antennomere IV straight; ventral margin of eye with large spinules; abdominal sternites without spinules or with few; sternite VII not emarginated; connexival spines short; proctiger long with short basolateral processes.

\section{Cylindrostethus podargus Drake, 1958}

Cylindrostethus podargus Drake, 1958: 110-111 [description].

Cylindrostethus stygius Drake, 1961: 65-66 [description], syn. nov.

\section{Material examined}

Data labels sent by email by Dr Thomas Henry. Holotype male (USNM): 'San Alejandro R.[,] Loreto, Peru [,]VII 58 [,] F. Woytkowski (White label)' 'Cylindrostethus podargus Drake[,] $\widehat{\jmath}$ '. (Photo by Thomas Henry). Allotype male (USNM): 'San Alejandro R. $\backslash$ Loreto, Pery $\backslash$ VII $58 \backslash$ F. Woytkowki' 'CJDrake $\backslash$ Coll. 1956' 'PubMed Allotype $\backslash$ Cylindrostethus $\backslash$ \& podargus $\backslash$ Drake'.

Other material examined. One male (SEMC): '[PERU]\ Rio San Alejandro $\backslash$ (Pampa Sacramento \Dept. Loreto July 1958\Woytkowski'; 

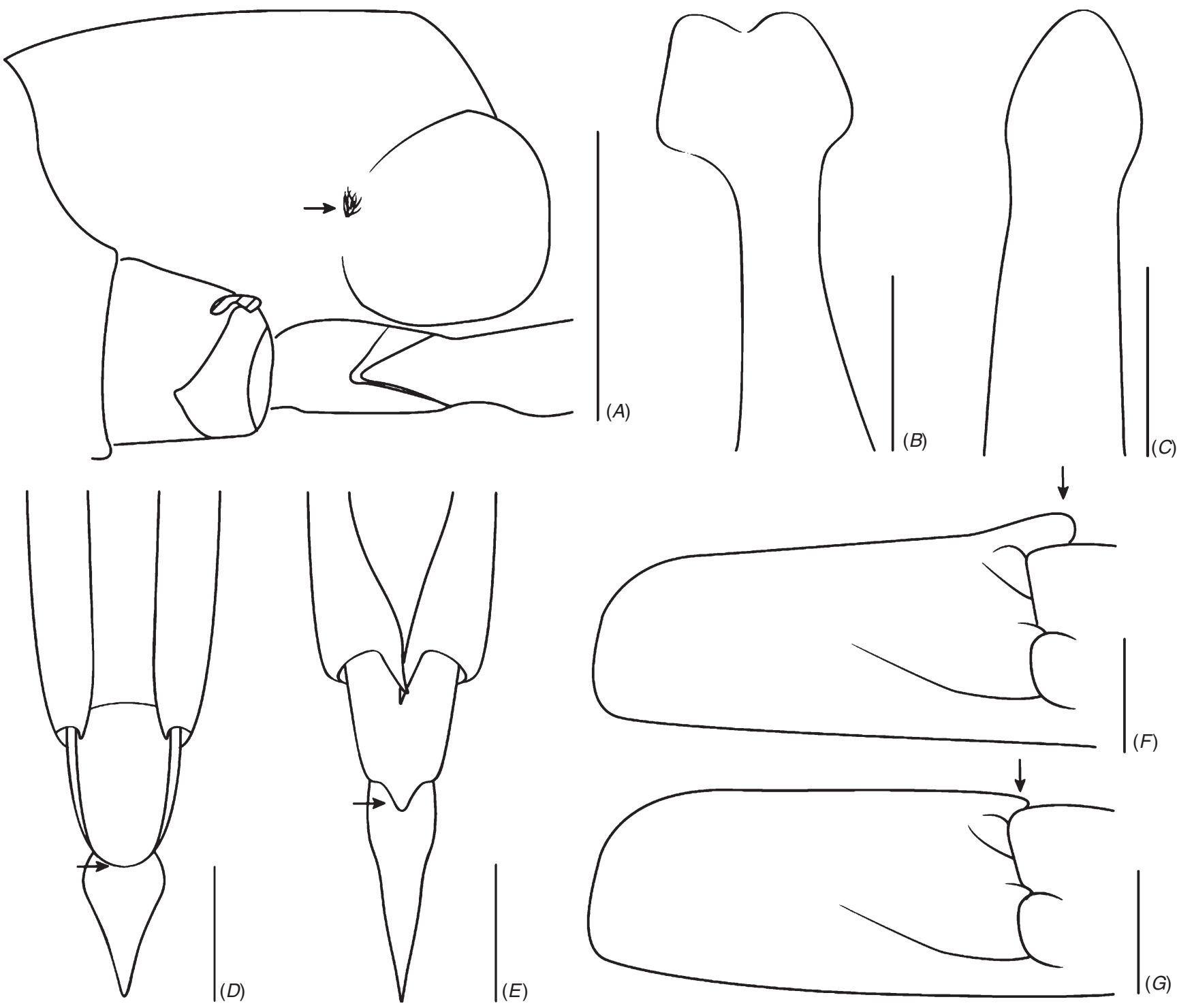

Fig. 2. (A) Cylindrostethus palmaris, detail of metanotum, ventral view; (B) C. hungerfordi (male), phallic sclerite, ventral view; (C) C. regulus (male), phallic sclerite, dorsal view; $(D)$ C. regulus (female), genitalia, dorsal view $(E)$ C. palmaris (female), genitalia, dorsal view $(F) C$. bilobatus (female), detail of mesonotum, lateral view; $(G)$ C. linearis (female), detail of mesonotum, lateral view.

one female (SEMC): '[PERU]\Rio San Alejandro\(Bampa Sacramento Dept. Loreto July 1958\Woytkowski' 'Locality: River San Alejandro (Bampa Sacramento) \Department of Loreto, Peru. \Date: July 1958.\Collector: Felix Woytkowski Note: the larger water striders were taken in the $\backslash$ middle of the river San Alejandro, far from the shores $\backslash$ in places of stronger current.'; one male and two females (MPEG): 'Brasil Rondônia $\backslash$ Porto Velho $\backslash$ Rio - Madeira $\backslash 23-V-1984$ ' 'Brasil Rondônia $\backslash$ Marclo Zanuto'; One male (MPEG): 'Brasil Rondônia \Porto Velho \Ig. Tabocal \M.E. R. (Rio) Madeira $23-V-1984$ ' 'Brasil Rondônia \Marclo Zanuto'.

Note on type material. Holotype in excellent state of preservation. Allotype with abdomen broken distal to the VIII segment.

\section{Diagnosis}

Pronotum with anteromedial yellow stripe (Figs. $(A, B)$. Males: basolateral processes of proctiger short, subquadrangular (Fig. 9A), directed sideways, $1.2-1.5 \times$ wider than long.

\section{Redescription}

Apterous. Body length: ô $17.3 \mathrm{~mm}$, of $18.8 \mathrm{~mm}$; distance between mesoacetabula: ô $2.2 \mathrm{~mm}$, $+2.3 \mathrm{~mm}$. Head: clypeus densely pilose (as in Fig. $4 A$ ); vertex not punctate (as in Fig. 4C); eyes $1.1-1.4 \times$ wider than interocular distance; ventral margin with inconspicuous spines (as in Fig. 4E); article III of rostrum covered with setae (Fig. 5C), 1.5-1.6× longer than article IV; antennomere I $1.9 \times$ longer than antennomeres II and III combined; antennomere III $2 / 5$ the length of antennomere IV, antennomere IV straight and wide, $\sim 4 / 5$ of head width (Fig. $6 \mathrm{C}$ ). Thorax: mesonotum $2 \times$ as long as pronotum and metanotum combined; anterodorsal region of prothoracic femora with fewer than 10 short spines; prothoracic tarsi slightly shorter than metathoracic tarsi; anterior area of metacetabula lacking tuft of setae. Male: lateral margins of abdomen slightly diverging 

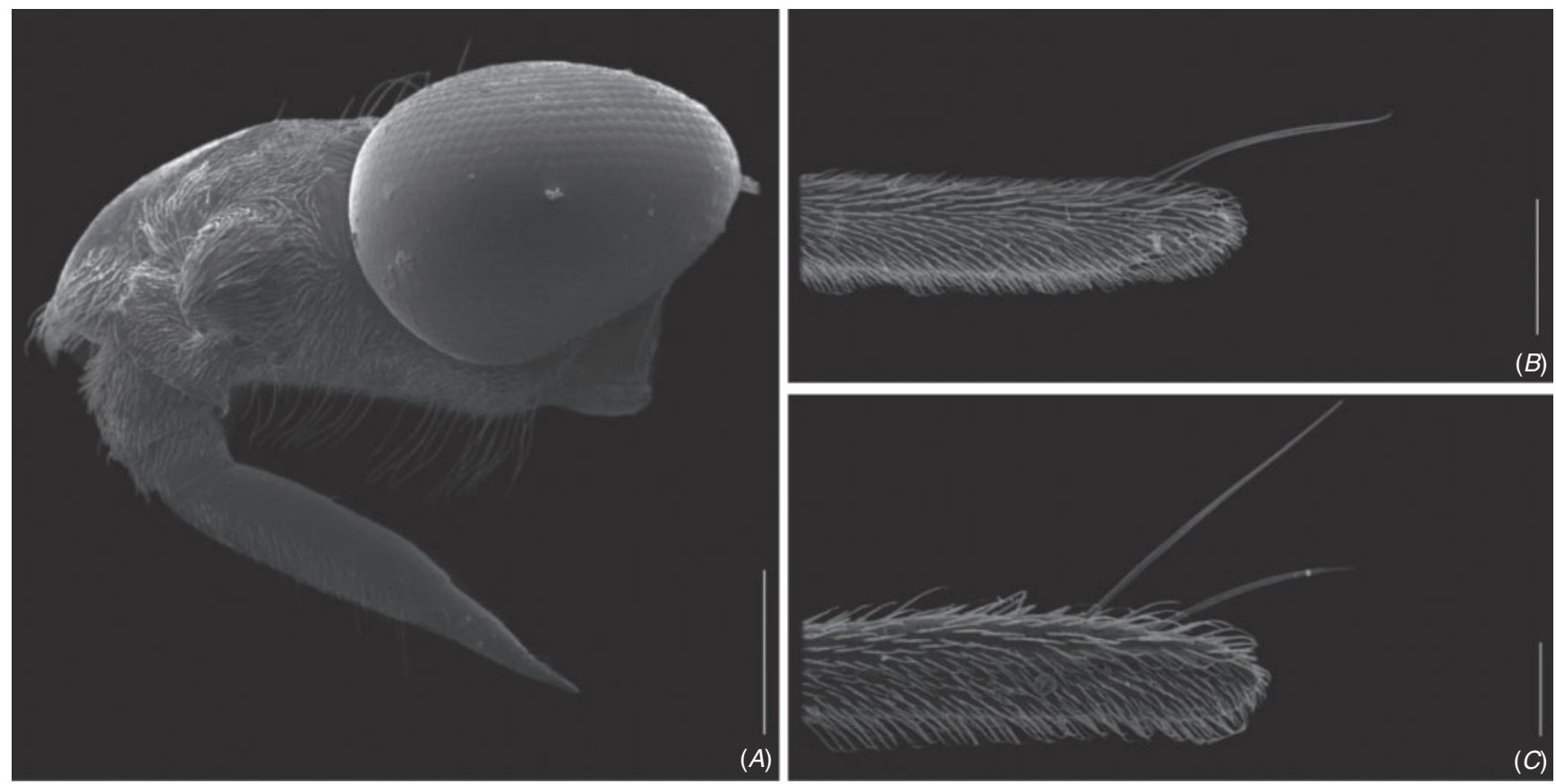

Fig. 3. Ultrastructure of head and thorax. (A) Cylindrostethus palmaris, head, lateral view; $(B)$ C. linearis, mesothoracic tarsomere II, lateral view; (C) C. palmaris, lateral view, detail of posterior tarsomere. Scale bar, Fig. $8=500 \mu \mathrm{m}$; Fig. 9 and Fig. $10=100 \mu \mathrm{m}$.

towards posterior region in dorsal view, tergite $\mathrm{VII} \sim 1.1 \times$ as wide as tergite II; sternites IV-VI lacking small spinules and concavities, sternites VII-VIII with few sparsely distributed spinules; tergite VII not depressed posteriorly; connexival spines $1 / 2$ the length of tergite VIII (Fig. $7 A$ ); sternum VII not emarginate at middle (Fig. $8 A$ ); lateral margins of tergite VIII parallel, convergent anteriorly, apex subquandragular (Fig. 8A), slightly constricted in ventral view; apex of pygophore rounded in ventral view (Fig. $8 A$ ); proctiger $2 \times$ as long as tergite VIII in dorsal view (Fig. 7A); basolateral processes short, subquadrangular (Fig. 9A) directed sideways, 1.2-1.5 $\times$ wider than long; phallus elongate, $2 \times$ longer than wide, sclerite basally bifid, branches $2 \times$ longer than the area of confluence. Female: posterior margin of mesonotum lacking large protuberances (Fig. 2G); tergite VIII elongate with a slightly rounded apex; gonocoxae with spines on posterior region; connexival spines $0.31 \mathrm{~mm}$ in length.

Colouration. Mostly black (Fig. 10A, B). Head: yellow dorsally, lighter between eyes; clypeus black; frons yellow (Fig. 14A); black ventrally; article I of rostrum light brown, article II dark brown, article III varying from brown to black (Fig. 15A). Thorax: pronotum with yellow stripe on anteromedial region; femora and tibiae yellow; mesonotum and metanotum black, covered with golden pubescence, with black longitudinal stripe on each side; mesopleuron, mesosternum, metapleuron and metasternum black, pleurites covered with slightly golden pubescence, sternites covered with slightly silver pubescence; meso- and metathoracic acetabula yellow; femora yellow, 1/6 of apical portion black. Abdomen: tergites and pleurites covered with golden pubescence, sternites covered with silver pubescence; tergites, pleurites and sternites (I-VII) black, apex of pleurite VII yellow; connexiva yellow in females, black in males, connexival spines black in both sexes. Male: basal area of tergite VIII black, apical area yellow; sternites and pygophore black, posterior region sometimes brown; central area of proctiger yellow. Female: tergite VIII yellow at lateral margins, brown at anterocentral region; dorsal region of gonocoxa yellow; central area of proctiger yellow.

\section{Comments}

Cylindrostethus podargus is easily distinguished from the other South American species by having: a black colouration (Fig. 10A, $B)$; apical margin of sternite VII not emarginate at middle (Fig. 8A) and sternites IV-VI without spinules. Drake (1958) described $C$. podargus (Fig. 16E) and three years later described C. stygius, syn. nov. (Drake 1961) (Fig. 16D). Both species are similar and we did not find substantial characters to differentiate them based on the original descriptions. Drake (1961) commented on differences among $C$. stygius, $C$. hungerfordi, $C$. palmaris and $C$. regulus, but did not even mention the previously described $C$. podargus. Additionally, the type specimens designated in both papers are identical (i.e. type locality, date and collector) (Fig. $16 F, G$ ). In fact, in the introduction of his 1961 paper, Drake mentions that there were seven Neotropical species of Cylindrostethus. However, he had previously described C. podargus (Drake 1958) and therefore, at that time, there would have been eight valid species, not seven. According to Drake (1961), type specimens were deposited at the USNM, but Thomas Henry (pers. comm.) has indicated that there are no such specimens in the collection. Marcela Monné photographed the female paratype of $C$. stygius deposited in 

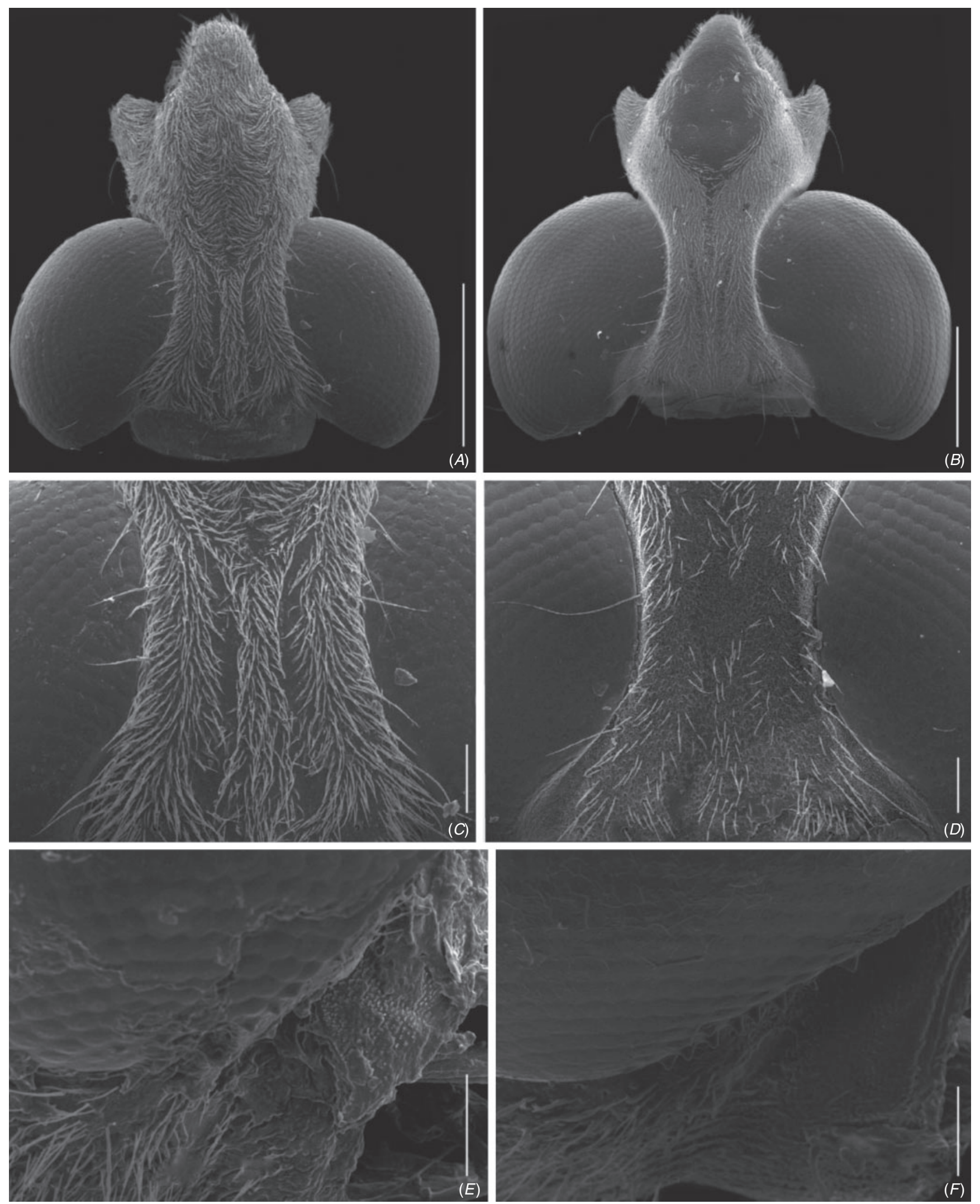

Fig. 4. Ultrastructure of the head. (A) Cylindrostethus linearis, dorsal view (B) C. hungerfordi, dorsal view; (C) C. linearis, dorsal view; $(D) C$. palmaris, dorsal view; $(E) C$. linearis, detail of eye margin, lateral view; $(F)$ C. palmaris, detail of eye margin, lateral view. Scale bar, Figs $11,12=500 \mu \mathrm{m} ;$ Figs $13-16=100 \mu \mathrm{m}$. 
the BMNH, and we confirmed that labels are identical to those in C. podargus Drake, 1958. Based on these findings, we consider C. stygius, syn. nov. as a junior synonym of $C$. podargus, considering that Drake likely described the same species twice from the same type series.

\section{Ecological notes}

The species is known from Peru (San Alejandro River). The specimens were netted in the swift flowing water, off the shore (Drake 1958).

\section{Cylindrostethus palmaris Drake \& Harris, 1934}

Cylindrostethus palmaris Drake \& Harris, 1934: 219, 222 [description, key]. Drake \& Harris, 1935: 3 [note]. Kuitert, 1942: 135, 136-137 [redescription, key]. Hynes, 1948: 343, 346 [note]; Kort-Gommers \& Nieser, 1969: 78, 79 [note, illustration]. Nieser, 1970: 118-119, 135, 137 [redescription, illustration]. Aristizábal, 2002: 81-86 [redescription, key, illustration]. Moreira et al., 2011a: 270, 273, 274 [redescription, illustration, key]. Moreira et al., 2011b: 6 [checklist].

\section{Material examined}

Paratype female (USNM). 'PARATYPE $\backslash$ Cylindrostethus $\backslash$ palmaris $\backslash$ D \& H (Red label, manuscript)' 'Cylindrostethus $\backslash$ palmaris D \& H. (Beige label, manuscript)' 'Cadras $\backslash$ Trinidad BW. I $\backslash$ Aug 20-21 (Beige label, manuscript)' 'Paratype No\} 5 1 1 0 6 \text { (manuscript)\U.S.N.M (Red label)' 'Aug. Busck〉 } Collector'.

Other material examined. Nine males, eight females (LACM): 'Imperatriz, on $\backslash$ Belém, Brasilia road $\backslash$ Maranhao, BRAZIL \July, 1960 D. L. Tiemann'; nine males, three females (LACM): '24 kil. E. Formoso,' Go., Brazil $\backslash$ May 21, 1956\F. S. Truxal' 'MACHRIS BRAZILIAN EXPEDITION - 1956\LOS ANGELES $\backslash$ COUNTY MUSEUM'; one male (SEMC): 'Brazil S. A $7-10$ 9-20-36' 'Vic. Joao Pessoa\(Sao Phelipe) \River Jurua $\backslash$ No. 375'; one male, one female (UEMS): 'Brasil, MS, Tacuru $\backslash$ Rio Iguatemi\I-2009\ Floriano'; One male (DZRJ): “\#42 Pleuston\15-V-2006 UFRJ Pronex'; one male (INPA): 'Brasil, AM, Manaus\ Rio Cuieiras 11 2.458650 lat $\backslash 60.34600$ long'; eight males (LACM): 'Jule 17, 1958, $42 \mathrm{~km} . \backslash$ SE. Maturis, Monagas \Venezuela $\backslash$ Arnold Menke'; one female (LACM): 'July 3, 1958, 42 Kms. \SE. Maturin, Monagas $\backslash$ Venezuela $\backslash$ Arnold Menke'; four males, one female (LACM): 'June 16, 1958, $42 \mathrm{~km} . \backslash$ SE. Maturim, Monagas \Venezuela\ Arnold Menke'; two males (USNM): 'Trinidad B. W. I. Oct. 27-29 1938\Carl J. Drake'; one female: 'Ama- Izonas; Rio Mavaca $\backslash$ Camp $65^{\circ} 06^{\prime} \mathrm{W} 2^{\circ} 2 \mathrm{~N}, 150 \mathrm{~m} .16 .27 .89^{\prime}$ 'Fhipps-FUDECI Exped.। by American Museum $\backslash$ of Natural History $\backslash$ D. A. Grimaldi, coli.'; one male, one female (AMNH): 'Berinitas $\backslash$ Dec 42 Venez $\backslash P$. Anduzee $\backslash$ Cylindrostethus $\backslash$ palmaris $\backslash$ Det. Drake' 'Donation from $\backslash$ J. A. Slater $\backslash$ Collection'; one male (USNM): 'Venezuela Exp.\Territ. Amazonas \Upper Cunucunuma \ulian May 27, 1950' 'J. Maldonado\Caprilles Coll.'; three males (DZUP) 'BR AM Presidente $\backslash$ Figueiredo $\backslash$ Lago do Poraque $\backslash 06-2011 \backslash$ Floriano'; one male (DZUP): 'BR-AM-Manaus $\backslash$ R. (Reserva) Ducke $\backslash$ Ig (Igarapé) Branquinho $\backslash$ 07-2011 Floriano'; one male (INPA): 'BR 174-61 km de \Manaus-AM $\backslash$ 24-01-77\ B. Mascarenhas' 'C. palmaris - INPA)' 'Cylindrostethus palmaris $\backslash$ D\&H 1934 \et. R. Sampaio1980'; seven males, five females (INPA): 'Brasil, AM, Manaus \MAO, IG(Igarapé) Conj.\Suframa IX 2003\Sampaio'; two males, two females (AMNH): 'GUYANA: Demerara District \Yarowkkabre Creek on Linden\Highway, June 16, 1986, K. \&\ R. Schimidt \& E. Traver, ex:\narrow stream with redwater $\backslash$ moderate current, no riffle'; one female (AMNH): 'Wismar,\Brit. Guiana\ V. 9 1936 Cylindrostethus $\backslash$ palmaris'; one male (AMNH): 'Georgetown, $\mathrm{BrM} \backslash$ II. 1922' 'Cylindrostethus $\backslash$ palmaris $\backslash$ C.J.D. D\&H'; one female (INPA): 'CEPLAC-estr. AM-10 Km 30- Manaus-BR' '18/VI/76 Mario Dantas'
'Gerridae' 'Cylindrostethus palmaris - INPA' 'Cylindrostethus palmaris D\&H, 1934\ det. R. Sampaio 1980'; four males, four females (INPA): 'BRASIL: Mato Grosso $\backslash$ Reserva Humboldt $\backslash 10^{\circ} 11^{\prime} \mathrm{S} 59^{\circ} 48^{\prime} 0 \backslash 75$-VII$1977 \backslash$ Norman D. Penny' 'Cylindrostethus palmaris - INPA' 'Cylindrostethus palmaris $\backslash$ D\&H, 1934 $\backslash$ det. R. Sampaio 1980'; one male (INPA): 'BRASIL: Amazonas $\backslash$ Reserva Campinas $\backslash$ 06/XI/1996\Bento Mascarenhas'; three males (USNM): 'Brazil.S.Amer.। Rio Caraguata) Matto Grosso [Mato Grosso do Sul] $\backslash$ March 15, 1953\F. Plaumann' ' $\widehat{o}$ ' PubMed; ' J C Lutz $\backslash$ Collection $\backslash 1961$ '; one male, one female (AMNH): 'Kobrene $\backslash$ M. Grosso, 947 J.C.M. Carbalho'; one male (INPA): 'Rio Paru Pará J.C.M. Carvalho'; one female (MPGE): ‘Brasil Pará Cap. Poço\Ig. (Igarapé) Braço $\backslash$ Do Curral 22 -IX-1987'; one male (MPEG): 'Brasil Pará Irituia Ig. Sta. Grande $\backslash 20 / X / 1987$ 'Brasil Pará \J. Dias'; one female (MPEG): 'Brasil Pará \S. Miguel do Guamá $I g$. do Sete $\backslash 19 \backslash X \backslash 1987$ '; two males, two females (MPEG): 'Brasil Pará \Serra Norte $\backslash$ Serraria-Ig. (Igarapé) Azul $\backslash 27$. VI-1985' 'PubMed Brasil Pará $R$ R N Neto'; two males (MPEG): 'Brasil Pará Serra Norte $\backslash$ Salobo $\backslash$ 04-VII-1984'; one female (MPEG): 'Brasil Pará \Serra Norte\ Est. Fofoca 07.V.1984' 'Brasil Pará \M.F. Torres'; one female (MPEG): 'Brasil Pará` Serra Norte \Caldeirão $\backslash 21-V I-1985$ ' 'Brasil Pará W. França'; two males, three females (MPEG): 'Brasil Parál Serra Norte\ Rio Itacaiunas $\backslash$ Caldeirão $\backslash 21-V I-1985$ ' 'Brasil Pará $\backslash$ P. Tadeu'; five males, two females (MPEG): 'Brasil Pará \Serra Norte $\backslash$ Pojuca II-VII-1984' PubMed 'Brasil Pará $\backslash$ M. F. Torres'; one male (MPEG): 'Brasil Mato Grosso $\backslash$ Chap. (Chapada) Guimarães $\backslash$ Faz. (Fazenda) Buriti.Coxipó $\backslash 10-\mathrm{V}-1984$ ' 'Brasil Mato Grosso $\backslash$ Marclo Zanuto'; three males, three females (MPEG): 'Brasil Pará \Serra Norte $\backslash$ Serraria $\backslash 27-V I-1985$ ' 'Brasil Pará $\backslash$ R. D. Thomaz'; one male (MPEG): 'Brasil MT $\backslash$ Chap. (Plateau) dos Guimarães $\backslash$ Colégio Agr. Buriti $\backslash 17-I I-1986 \backslash$ Col. I. S. Gorayeb'; one male (MPEG): 'Brasil Mato Grosso \Rod. AR 1 Vilhena Juína IG. (Igarapé)__ 3\16-V-1984' 'Brasil Mato Grosso' 'B. Mascarenhas'; one male, one female (MPEG): 'Brasil Mato Grosso \Chap. (Chapada) dos Guimarães $\backslash$ Faz. Coxipó $\backslash 10-\mathrm{V}-1984$ ' 'Brasil Mato Grosso \Marclo Zanuto'; five males, two females (INPA): 'Brasil: PA Sem. Pio $X \backslash 11-\mathrm{VI}-1975 \backslash$ B. Mascarenhas' 'C. palmaris - Inpa' 'Cylindrostethus palmaris $\backslash$ D\&H, 1934\det. R. Sampaio 1980'; one male, one female (AMNH): 'BRASIL: PARA, $\backslash$ Sta. Isabel $\backslash$ B. Mascarenhas' 'I nov 1973\Igarapé corrente \na mata'; one male (MPEG): 'Pará Carajás $\backslash$ Est. Tres Alfa- $\backslash 28 . I V .1983 \backslash$ Tacainha km 5\Macarenha and collegues'; two males, four females (SEMC): 'British Guiana $\backslash$ Supuruni Creek $\backslash$ Aug. 1937 $\backslash$ S. Harris '(§)' 'PARAMORPHOTYPE $\backslash$ Cylindrostethus $\backslash$ palmaris $\backslash$ L. Kuitert'; five males, six females (SEMC): 'Bolivia S. A.। R. Beni Cachuela Esperanza 9-37\ A. M. Olalla' 'PARAMORPHOTYPE $\backslash$ Cylindrostethus $\backslash$ palmaris $\backslash$ L. Kuitert'; one female (SEMC): 'Bolivia S. A.\ R. Beni Cachuela Esperanza 9-37\ A. M. Olalla' 'ALLOMORPHOTYPE $\backslash$ Cylindrostethus palmaris $\backslash$ L. Kuitert'.

Notes on types. The paratype is poorly preserved: right antennomeres III-IV, left antennae, right mesothoracic leg and left mesothoracic tarsi are missing; the head is reattached (glued) to specimen.

\section{Diagnosis}

Polymorphic with respect to presence or absence of wings (Fig. 10C-F); male: basolateral processes of proctiger small, directed sideways, as wide as large, almost semicircular in shape (Fig. 9B). Female: apex of tergite VIII acute (Fig. 2E).

\section{Redescription}

Apterous or winged. Apterous form: body length $\hat{\sigma} 17.5 \mathrm{~mm}$, $q$

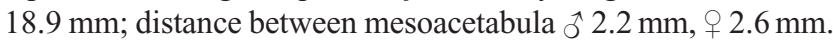
Head: clypeus glabrous (as in Fig. 4B); vertex punctate (Fig. 4D); eyes 1.5 to $2.1 \times$ as wide as interocular distance; ventral margin with conspicuous spines (Fig. 4F); rostrum: article III with sparsely distributed setae (as in Fig. 5A), 1.7-2.3× longer than article IV; antennomere I 1.3-1.6 $\times$ longer than antennomeres II 

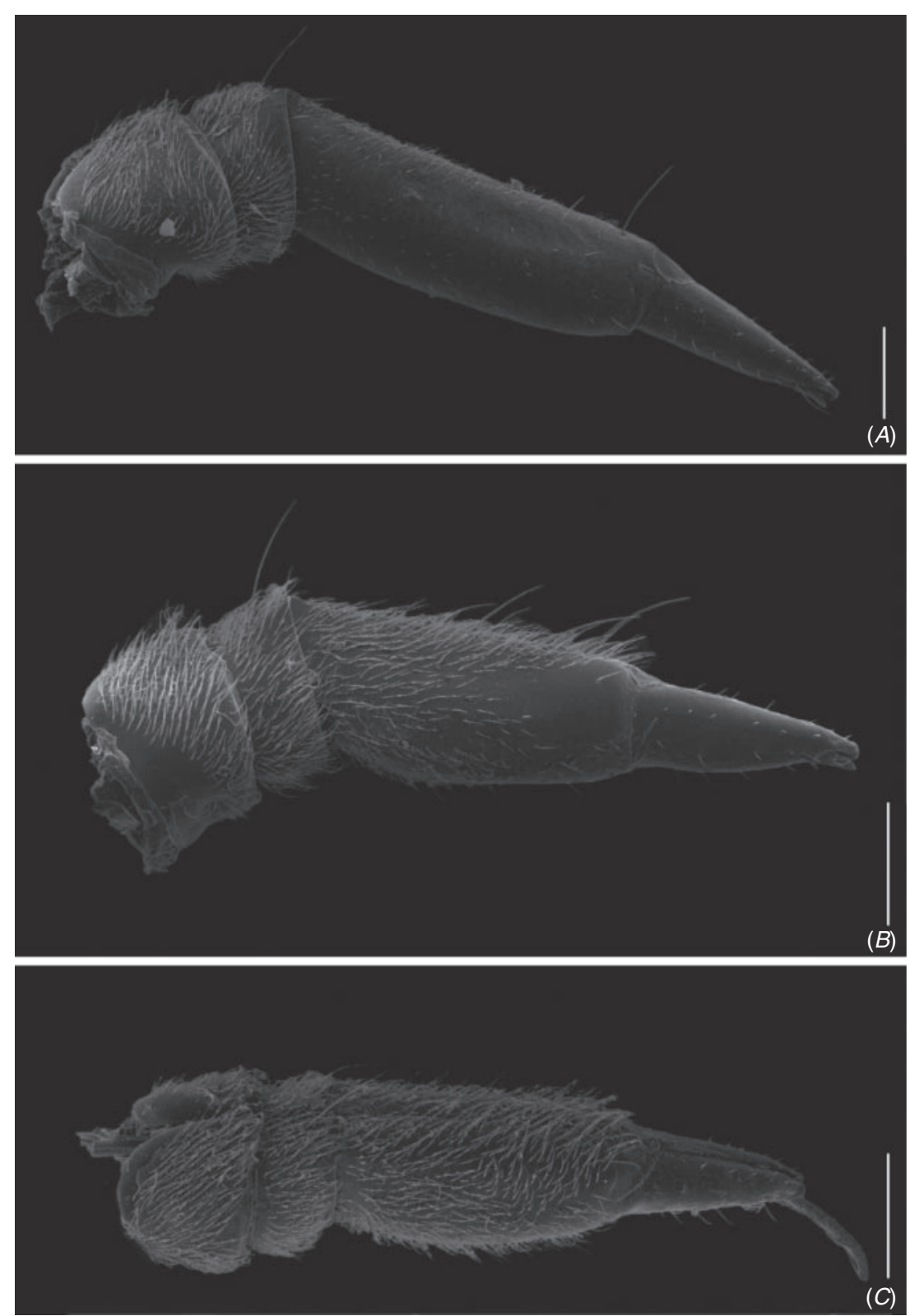

Fig. 5. Ultrastructure of the rostrum, lateral view. (A) Cylindrostethus hungerfordi; (B) C. linearis; (C) C. podargus. Scale bar $=200 \mu \mathrm{m}$.

and III combined; antennomere III $\sim 3 / 5$ the length of antennomere IV, antennomere IV straight, 3/5 of head width (as in Fig. $6 B$ ). Thorax: mesonotum $1.3-1.5 \times$ longer than pronotum and metanotum combined; anterodorsal region of prothoracic femora often showing more than 15 short spines; prothoracic tarsi longer than metathoracic tarsi; anterior region of metacetabula with a tuft of setae (Fig. 2A). Male: lateral margins parallel or slightly convergent in dorsal view, tergite II 4/5-1× wider than tergite VII; sternites IV-VI lacking small spinules and central concavities; tergite VII not depressed on the posterior quarter; connexival spine 0.4-0.6 smaller in length than tergite VIII (Fig. 7B); sternites VII-VIII with or without a small number of spines; posterior margin not emarginate at middle (Fig. $8 B$ ); lateral margins of tergite VIII parallel or converging towards anterior and posterior regions, posterior margin rounded (Fig. 7B); apex of pygophore varying from rounded to nearly acute, in ventral view (Fig. $8 B$ ); proctiger $2 \times$ longer than tergite VIII, in dorsal view (Fig. $7 B$ ), basolateral processes short, directed sideways, as wide or wider than long, suboval (Fig. 9B); phallus elongate, $\sim 2 \times$ as long as wide, sclerite bifid basally, branches $2 \times$ longer than area of confluence. Female: posterior margin of mesonotum lacking large protuberances on posterior region (Fig. 2G); tergite VIII elongated, apex slightly acute (Fig. 2E); posterior region of gonocoxae with spines; connexival spine varying $0.5-0.7 \mathrm{~mm}$ in length. 

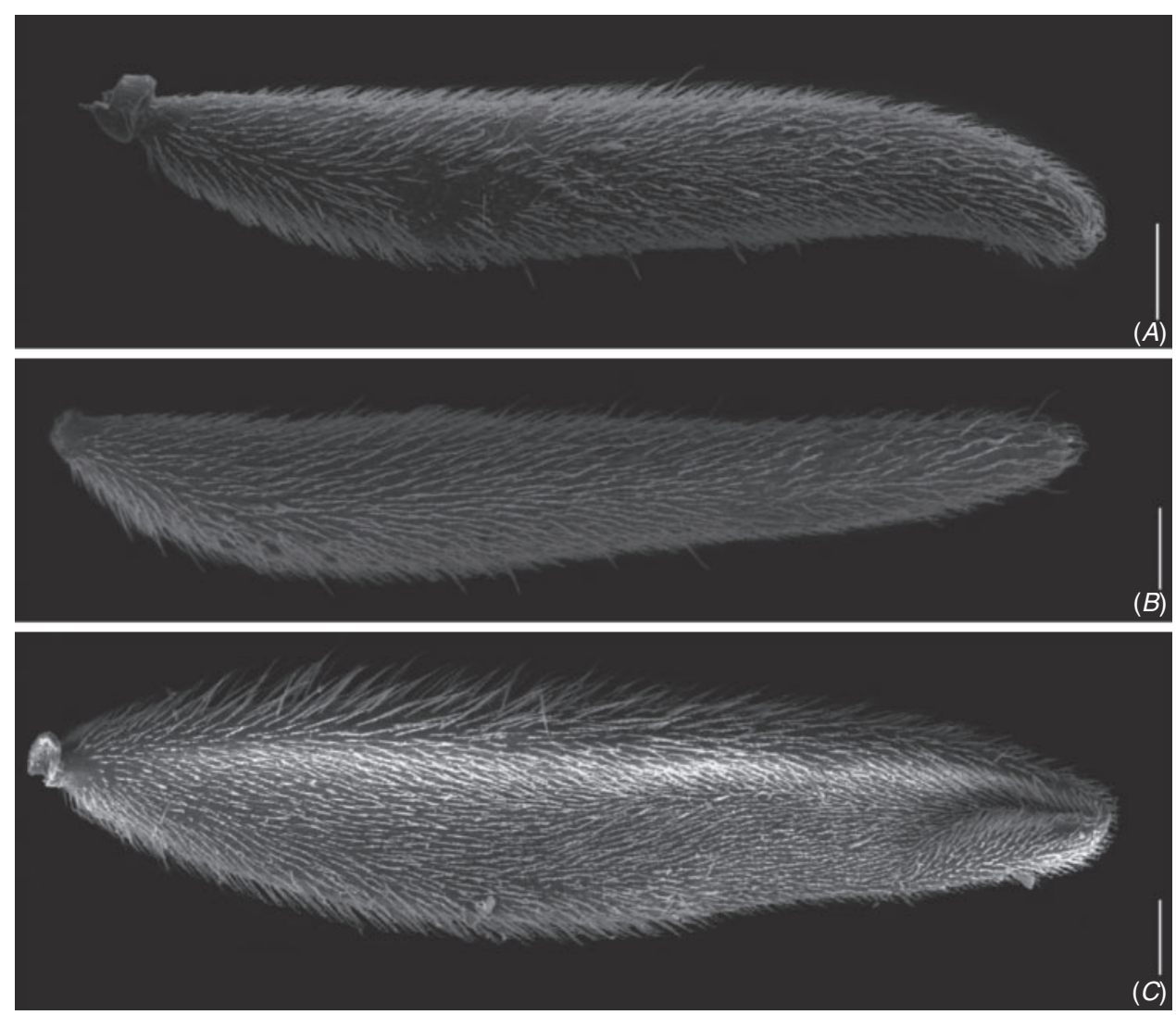

Fig. 6. Ultrastructure of the IV antennomere, lateral view. (A) Cylindrostethus linearis; (B) C. palmaris; (C) C. podargus. Scale bar $=100 \mu \mathrm{m}$.

Colouration (apterous form). Mostly yellow (Fig. 10C, D). Head: in dorsal view, yellow, varying from entirely yellow to black at frons (Fig. 14B); yellow ventrally; articles I and II of rostrum yellow, $1 / 3$ or $2 / 3$ of the posterior region of article III black, anterior region yellow (Fig. 15B). Thorax: pronotum with median yellow spot; femora and basal portion of tibiae yellow; mesonotum and metanotum with black longitudinal stripes, wider than median yellow stripe; mesopleuron, mesosternum, metapleuron and metasternum yellow; mesothoracic and metathoracic acetabula with a laterodorsal brown spot; mesothoracic and metathoracic femora yellow, with black longitudinal stripe on dorsal and ventral region, inconspicuous in specimens of lighter colouration. Abdomen: covered with light brown pubescence; tergites (I-VII) black, sometimes with slightly marked median longitudinal yellow stripe; connexiva, pleurites and sternites (I-VII) yellow; pleurites sometimes showing black dorsolongitudinal stripe. Male: tergite VIII yellow, black at centroposterior region, or black at centroposterior region and at apex; sternite VIII yellow; pygophore yellow, or black apically; proctiger black, with basolateral processes and anterior region yellow. Female: tergite VIII yellow, black apically, or brown at central area; gonocoxae varying from yellow to brown, ventral region usually black; proctiger black, often yellow at margin and apex.
Winged form. Body length: $\hat{\sigma}^{\wedge} 18.2 \mathrm{~mm}, \propto 19.3 \mathrm{~mm}$; distance

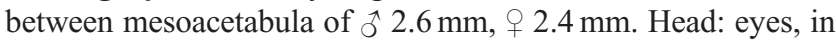
dorsal view, $1.8-2.0 \times$ wider than interocular distance; article III of rostrum 2.0-2.3 $\times$ longer than article IV; antennomere I 1.3-1.5 $\times$ longer than articles II and III combined. Thorax: male: lateral margins of abdomen convergent towards the posterior region in dorsal view, tergite II $0.7-0.8 \times$ wider than tergite VII; connexival spines $0.4-0.6 \times$ smaller than length of tergite VIII; basolateral processes $1.1-1.5 \times$ wider than long. Female: connexival spines $0.4-0.6 \mathrm{~mm}$ in length.

Colouration (winged form). Pronotum with yellow heartshaped spot on anterior region, otherwise similar to apterous specimens (Fig. 10E, F).

\section{Comments}

Cylindrostethus palmaris differs from other Neotropical Cylindrostethus in possessing wing polymorphism (Fig. $10 C-E$ ). It superficially resembles $C$. hungerfordi and C. regulus, but differs in having basolateral processes of the proctiger with length subequal to width (in males) (Fig. 9D); phallus elongated, and branches of sclerite $\sim 2 \times$ larger than its confluence area. It differs from $C$. hungerfordi in having black stripes on the mesonotum, more or less as large as median yellow stripe (Fig. 11A, B); the apical margin of phallic 

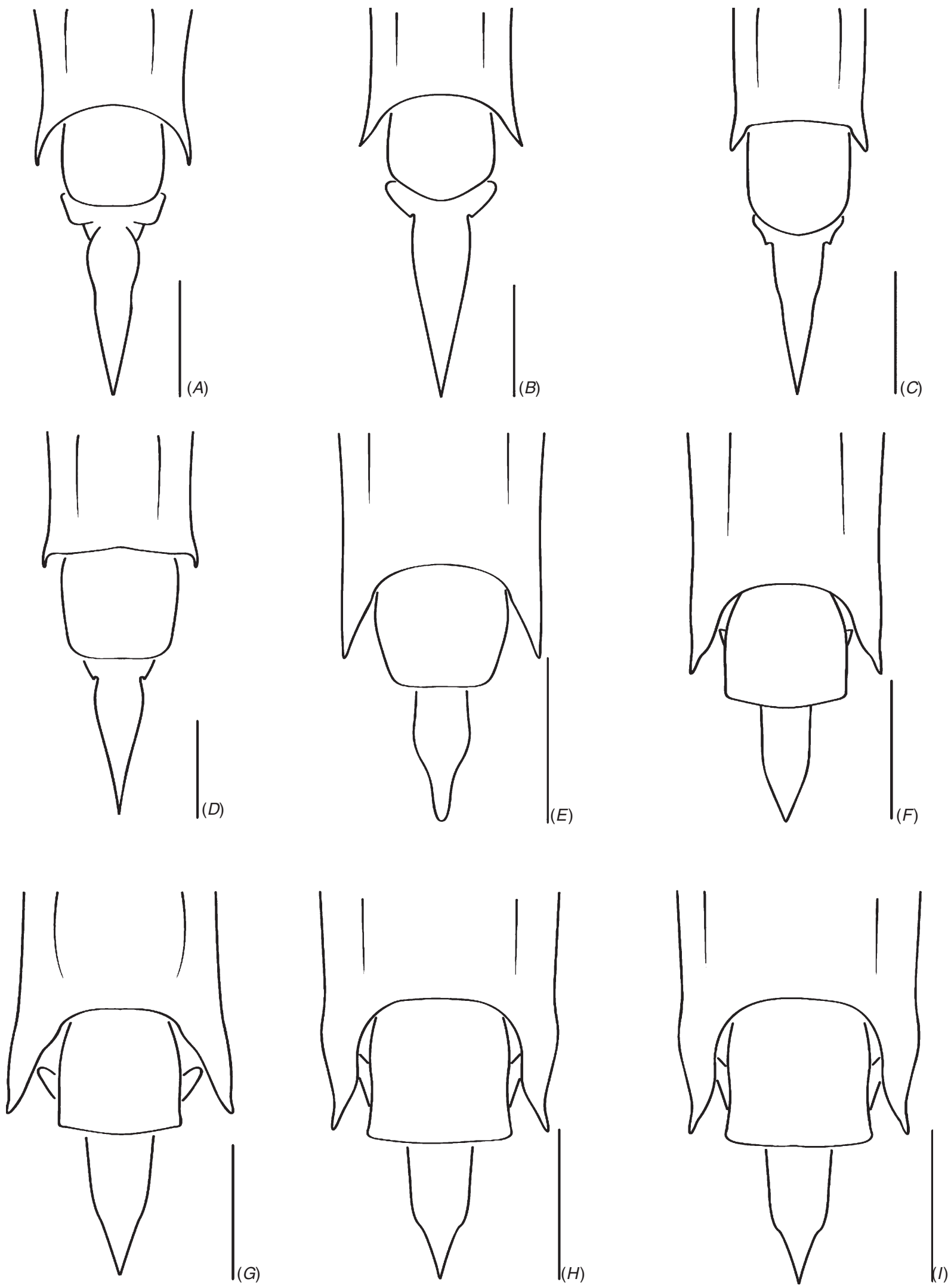

Fig. 7. Male genitalia, dorsal view. (A) Cylindrostethus podargus; (B) C. palmaris; (C) C. hungerfordi; (D) C. regulus; (E) C. bilobatus; $(F)$ C. meloi; $(G)$ C. bassleri; $(H)$ C. linearis; $(I) C$. drakei, sp. nov. Scale bar $=1 \mathrm{~mm}$. 

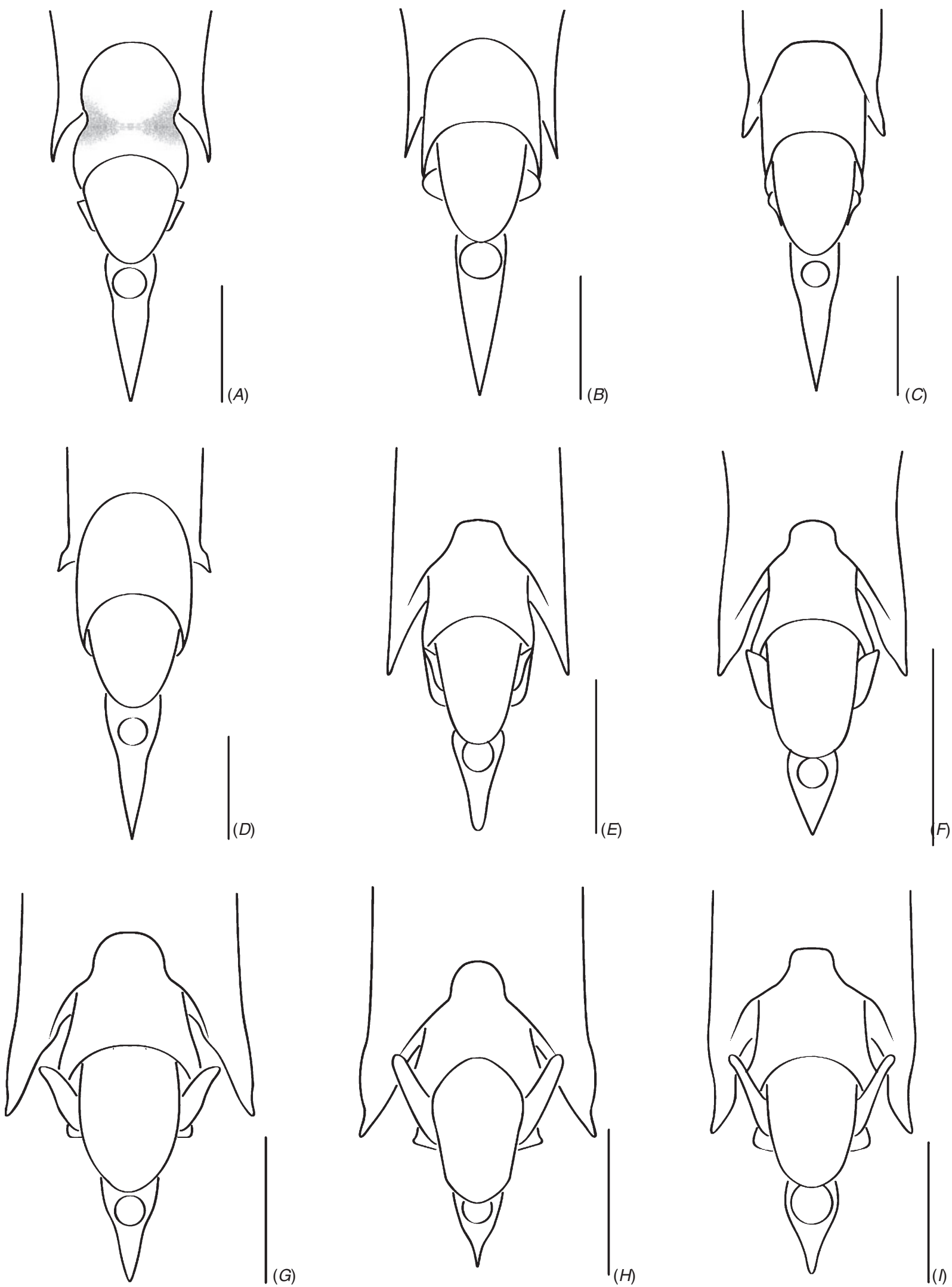

Fig. 8. Male genitalia, ventral view. (A) Cylindrostethus podargus; $(B)$ C. palmaris; $(C)$ C. hungerfordi; (D) C. regulus; $(E)$ C. bilobatus; $(F)$ C. meloi; $(G)$ C. bassleri; $(H)$ C. linearis; (I) C. drakei, sp. nov. Scale bar $=1 \mathrm{~mm}$. 

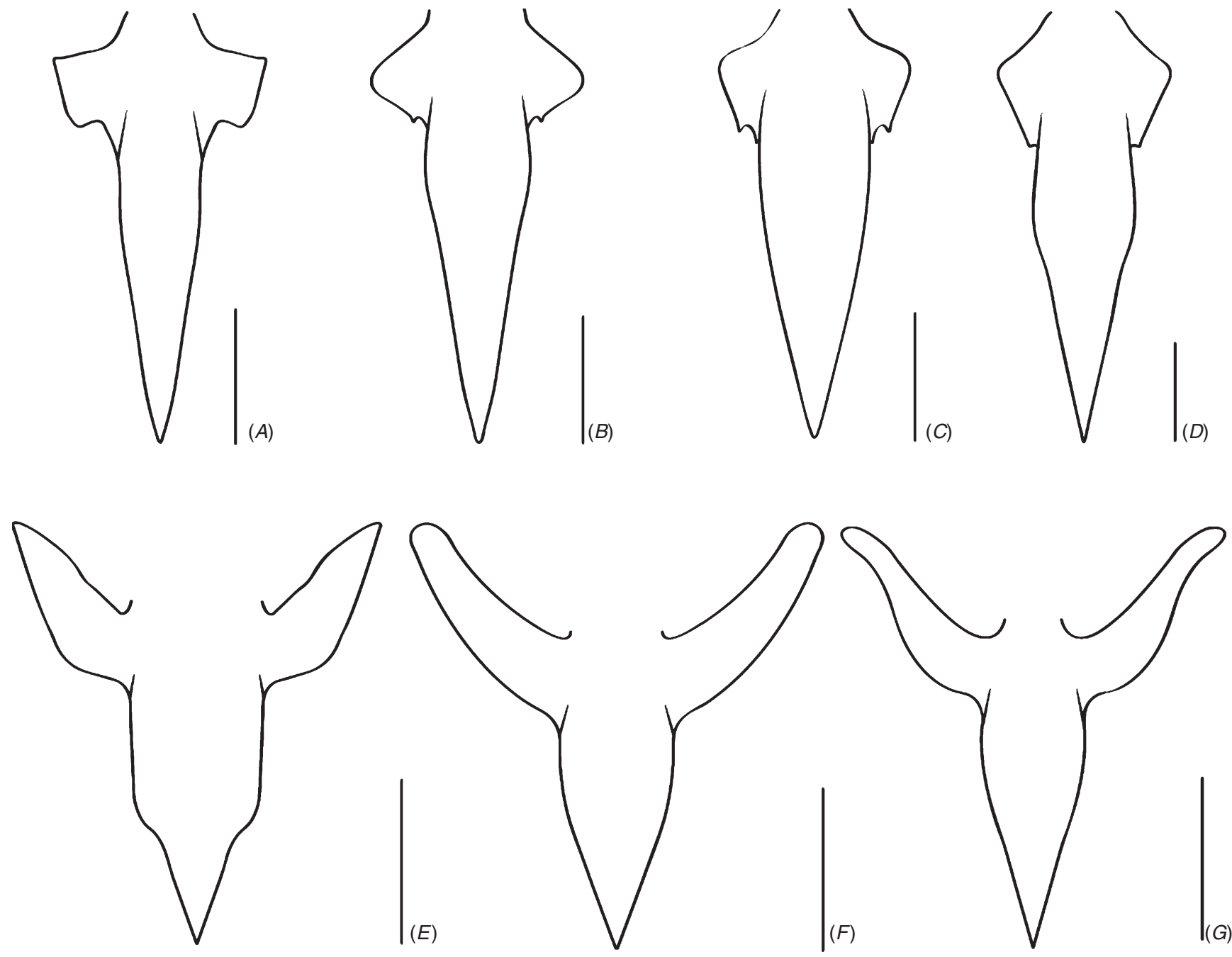

Fig. 9. Proctiger of males, dorsal view. (A) Cylindrostethus podargus; $(B)$ C. palmaris; $(C)$ C. hungerfordi; (D) C. regulus; $(E) C$. meloi; $(F)$ C. linearis; (G) C. drakei, sp. nov. Scale bar $=0.5 \mathrm{~mm}$.

sclerite is also not broad and emarginate (Fig. 2B). It differs from $C$. regulus in the smaller body size; the anterior black tibiae, and tergite VII not depressed apically in males.

\section{Ecological notes}

This species is widely distributed, and can be found in rivers, streams and ponds. Some specimens were collected in the Iguatemi River (Mato Grosso do Sul State, Brazil), in shady areas of small forest stream with moderate flow. We collected it in deep parts of the forest stream and also near the margins. In the Branquinho Stream (Amazonas State, Brazil), specimens were in shallow areas with moderate flow and sandy substrate; the width between the stream margins was $1.5 \mathrm{~m}$. Specimens were also collected in a lake without riparian forest, but was shaded by concrete pipe. Hynes (1948) reported that C. palmaris specimens were collected in deep ponds and heavily shaded streams, where they are very agile. Cylindrostethus palmaris and $C$. regulus are sympatric in Jurua River (Amazonas states, Brazil).
Cylindrostethus hungerfordi Drake \& Harris, 1934

Cylindrostethus hungerfordi Drake \& Harris, 1934: 221 [description]. Kuitert, 1942: 135-136 [key to species, taxonomic notes]. Nieser, 1970: 117, 137 [redescription, illustration]. Moreira et al., 2011b: 6 [checklist].

\section{Material examined}

Holotype male (SEMC). 'New Amsterdam, VII-1930, F.X. Willians Cylindrostethus hungerfordi Type D \& H $\backslash$ British Guiana S.A Near New Amsterdam. July 301923 F.X. Willians'.

Paratype female (SEMC). 'New Amsterdam, VII-1930, F.X. Willians Cylindrostethus hungerfordi Type D \& H $\backslash$ British Guiana S.A Near New Amsterdam. July 30 1923 F.X. Willians'.

Other material examined. One male (INPA): 'Serra do Navio $\backslash$ (I.C.O. M.I) \Amapá-II-961-4/61 J.C.M. Carvalho col.'; four males (AMNH): 'Guyana: Essequibo Prov; Little Takutu R. at main $\backslash$ road from logging cmpnd $\backslash$ Aug. 15, 1983 K. Schmidt $\backslash$ On deep \& narrow, swift river without rapids'; one male (AMNH): 'FR. GUIANA [Suriname]: Lawa River shores $\backslash$ opp. Anapaike Village, muddly $\backslash$ riv. Str. w/ rot. Foliage $\backslash 22$. 

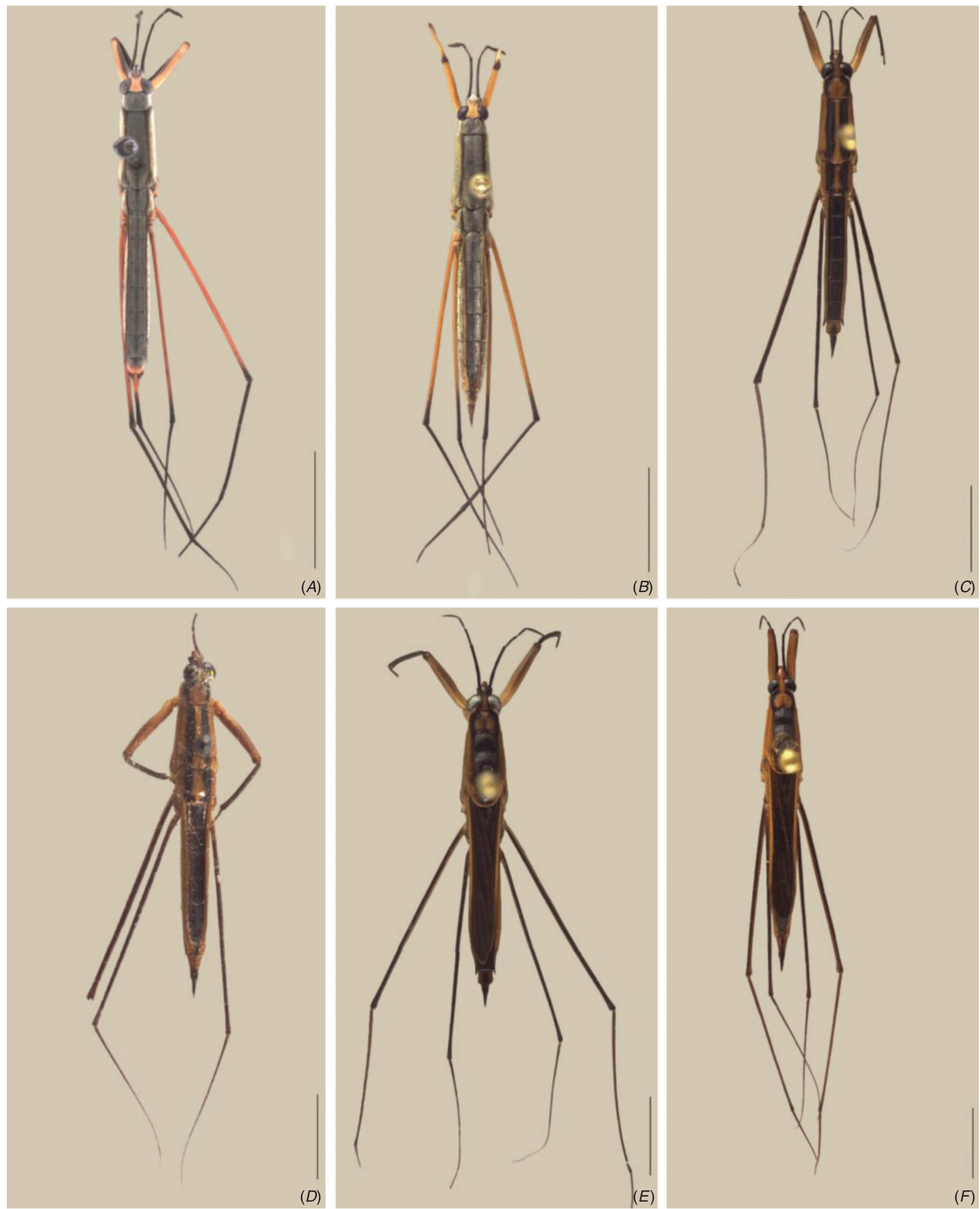

(C)

Fig. 10. (A) Cylindrostethus podargus (male holotype) (image provided by Michele Touchet); (B) C. podargus (female); (C) C. palmaris (male, apterous form); (D) C. palmaris (female paratype, apterous form); $(E)$ C. palmaris (male), winged form; $(F)$ C. palmaris (female) winged form. $\mathrm{Scale}$ bar $=5 \mathrm{~mm}$. 

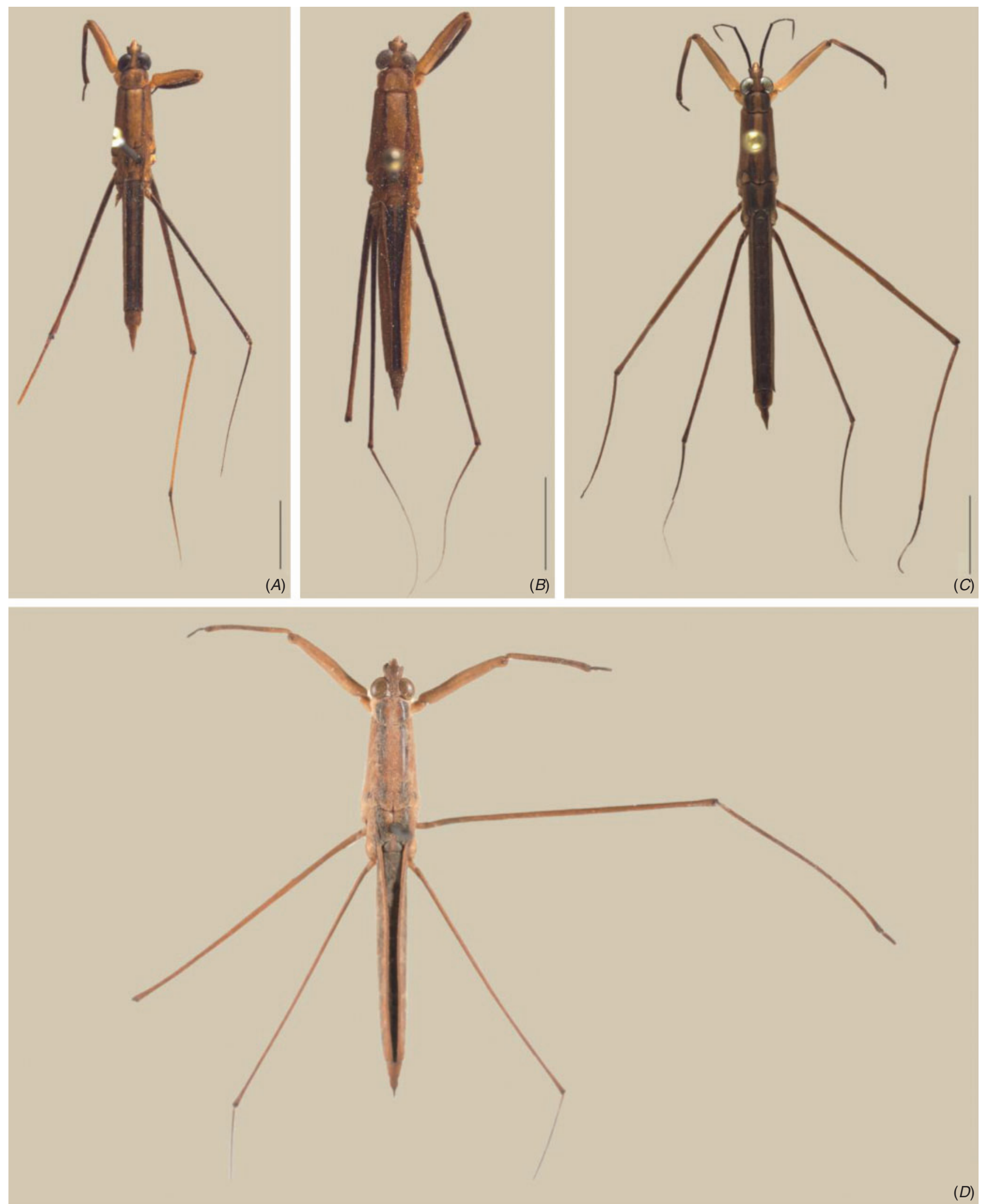

Fig. 11. Body, dorsal view. (A) Cylindrostethus hungerfordi (male holotype); (B) C. hungerfordi (female paratype) (image provided by Dra. Marcela Laura Monné Freire); (C) C. regulus (male); (D) C. regulus (female syntype). Scale bar $=5 \mathrm{~mm}$. 
XI.1963, B. Malkin' 'FRENCH GUIANA: Lawa river\ shores opposite Anapaike $\backslash$ village, muddy river stream $\backslash$ with much rotted foliage. $\backslash$ Nov. 22, 1963\ B. Malkin'; one female (AMNH): 'FR. GUIANA: Lawa River shores $\backslash$ opp. Anapaike Village, muddly $\backslash$ riv. Str. w/ rot. Foliage $\backslash 22 . X I .1963$, B. Malkin'; one female (SEMC): 'Dutch Guiana VIII.19.1943\D.C.Geiskcs' 'With Mts, line $\backslash 1 \mathrm{~km}$ 62e kamp $\backslash$ Sanderesk' 'Cylindrostethus $\backslash$ hungerfordi $\backslash$ ORA det. Calabrese 1972'.

Notes on types. The holotype is severely damaged; antennae, left metathoracic leg and left mesothoracic tarsus are absent. In the paratype, the left prothoracic legs and mesothoracic tibiae are missing.

\section{Diagnosis}

Pronotum with two black anterolateral spots; anterior region of prothoracic femora bearing more than 30 minute spines; mesonotum with narrow, longitudinal black stripes, $3 \times$ as narrow as yellow median stripe (Fig. 11A, B), basolateral processes short, directed sideways, $\sim 2 \times$ as wide as long (Fig. 9C); apex of phallus sclerite long and emarginate at the middle (Fig. 2B).

\section{Redescription}

Uniformly apterous; body length: ô $19.6 \mathrm{~mm}$, q $19.7 \mathrm{~mm}$; distance between mesoacetabula: o $2.8 \mathrm{~mm}$, $q 2.9 \mathrm{~mm}$. Head: clypeus glabrous (Fig. 4B); vertex punctate (as in Fig. 4D); eyes $1.8-1.9 \times$ as wide as interocular distance, ventral margin showing conspicuous spines (as in Fig. 4F); article III of rostrum 1.8-2 $\times$ longer than IV, covered with small, sparsely distributed setae (Fig. 5A); antennomere I $1.5 \times$ longer than antennomere II and III combined; antennomere III $\sim 3 / 5$ the length of antennomere IV, antennomere IV straight, 7/10 of head width (as in Fig. 6B). Thorax: mesonotum $1.4 \times$ longer than pronotum and metanotum combined; anterodorsal region of prothoracic femora usually bearing more than 30 minute spines; prothoracic tarsi $1.6 \times$ as long as metathoracic tarsi; anterior region of metacetabula with a tuft of setae (as in Fig. 2A). Male: lateral margins of abdomen parallel or slightly convergent in dorsal view, tergite VII $0.9-1 \times$ as wide as tergite II; sternites IV-VI lacking spinules and concavities, tergite VII not depressed at posterior fourth; connexival spines $3 / 10 \times$ smaller than length of tergite VIII; sternite VII not emarginate at middle (Fig. 8C); lateral margins of tergite VIII converging towards basal and apical regions, apex rounded (Fig. 7C); apex of pygophore rounded in ventral view (Fig. $8 C$ ); proctiger $\sim 2 \times$ as long as tergite VIII (Fig. $7 C$ ), basolateral processes short, directed sideways, $1.96-2.2 \times$ as wide as long (Fig. 9C); phallus slightly rounded, more or less as wide as long, branches of sclerite approximately as wide as its confluence area, apex of sclerite broad and emarginate medially (Fig. 2B). Female: posterior margin of mesonotum lacking large protuberances (Fig. $2 G$ ); tergite VIII elongate, apex slightly rounded; posterior region of gonocoxae bearing spines; connexival spines $0.4-0.5 \mathrm{~mm}$ in length.

Colouration. Mostly yellow (Fig. 11A,B). Head: yellow in dorsal view, lateroposterior region of clypeus black (Fig. 14C), yellow in ventral view; I, II and basal $2 / 3$ of article III of rostrum yellow, others black (Fig. 15C). Thorax: pronotum dotted black on anterolateral region; femora and basal area of tibiae yellow; mesonotum with longitudinal black stripes $3 \times$ narrower than median yellow stripe; mesopleura and mesosternum yellow; metanotum black with longitudinal stripes $2 \times$ narrower than median yellow stripe, mesopleuron and metapleuron yellow; meso- and metathoracic acetabula with laterodorsal brown spot; meso- and metathoracic femora yellow, black longitudinal stripes ventrally and dorsally. Abdomen: covered with light brown pubescence; tergites I-VII with median longitudinal yellow stripe (as wide as lateral black stripes in males, and distinctly narrow in females); connexiva, pleurites and sternites I-VII yellow. Male: tergite and sternite VIII, pygophore and proctiger yellow, apex of tergite VIII black. Female: tergite VIII, proctiger and gonocoxae yellow, apex of tergite VIII black.

\section{Comments}

This species superficially resembles $C$. palmaris and C. regulus; however, it differs in having black stripes on the mesonotum, $3 \times$ narrower than the median yellow stripe (Fig. 11A, B). In males, the apical margin of the phallic sclerite is broad and emarginate (Fig. 2B). It is also much smaller than $C$. regulus; the tibiae lack black stripes, and the tergite VII is not depressed apically. It differs from $C$. palmaris in having the basolateral processes of the proctiger $2 \times$ as wide as long (Fig. 9C); the rounded phallus, and the sclerite branches of the phallus as long as the width of its confluence area.

\section{Cylindrostethus regulus White, 1879}

Hydrobates regulus White, 1879a: 488 [description]; White, 1879b: 269 [taxonomic notes].

Cylindrostethus regulus Kirkaldy \& Torre-Bueno, 1909 [nov. comb.]. Drake \& Harris, 1930: 238 [redescription]. Drake \& Harris, 1934: 219, 222-223, 238-239 [redescription, key, illustration]. Kuitert, 1942: 137 [taxonomic notes]. Moreira et al., 2011a: 270, 273, 274, 276. [redescription, key, illustration]. Moreira et al., 2011b: 6 [checklist].

\section{Material examined}

The type series was photographed by Dr Marcela MONNÉ, and the photographs were examined in this study. Syntype, female (BMNH): 'Hydrobates \regulus B.W. \TYPE' (white label, handwritten) 'Pres. by Perth Museum. \ B.M. 1953-629' (white label, handwritten) 'Labria R. Purus \10/9-74 \Traill' (white label, handwritten) 'Hydrobates regulus' (yellow label, handwritten) 'SYN- $\backslash$ TYPE' (white label, outlined in light blue) 'Type' (white label, outlined in red) 'BMNH $\backslash \# 1005956$ ' (white label) 'Hydrobates regulus B. W' (white label, manuscript); syntype female (BMNH): 'Hydrobates $\backslash$ regulus B. W. \Paratype.' (white label) 'Pres.by $\backslash$ J. Ritchie \Curator Perth Mus. \B. M. 1929-79.' (white label) 'Labria \} R. Purus $\backslash$ 16.9.74 \Traill' (yellow round label, handwritten) 'Para- $\backslash$ type' (white label, outlined in yellow) [probably this label was placed by the museum curator posteriorly to the syntypes designation] 'SYN- $\backslash$ TYPE' (white label, outlined in light blue) 'BMNH (E) \\#1010360' (white label).

Other material examined. Two males, three females (SEMC): 'Brazil S.A \Jan - Apr. 1036 $\backslash$ A. M. Olalla $\backslash$ No 1' 'R. (Rio) Amazonas (Nite) $\backslash$ Region de $\backslash$ Itacoatiara'; two males, one female (SEMC): 'Brazil S. A 9-25, 10-17-36 $\backslash$ A.M. Olalla' 'Vle. Santo $\backslash$ Antonio, River $\backslash$ Eiru No. 3711'; three females (SEMC): 'Brazil S. A 7-10 9-20-26\A. M. Olalla' 'Vle. Joao Pessoa (São Phelipe) [Eurinepe] River Jurua \No. 375'; two males, one female (UPTC): 'Colombia, Putamayo\Puerto Leguizano \Caseiro \Bajo Casacunte $00^{\circ} 04^{\prime} 45.8-74^{\circ} 59^{\prime} 43^{\prime} 9$ ' ‘ $178 \mathrm{~m}$ (metros) $\backslash 19-11-2008 \backslash$ Jiménez (UPTC) col.'; two males, one female (INPA): 'BR, AM, Coari, Urucu, Ig.

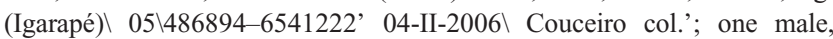


one female (AMNH): 'PERU: Dept. (Departamento) Loreto: $\backslash$ Rio Loreto Yacu, $\backslash$ may 3, 1970, forest $\backslash$ streem, B. Malkin'; one male (DZRJ): '2057'.

Notes on types. Syntype lacking antennae and left mesothoracic tibiae and other syntypes lacking III-IV antennomere and left mesothoracic legs.

White $(1879 a)$ did not designate types in his description of C. regulus, and based his description on a series of specimens, so all are syntypes. However, some specimens were wrongly labelled as paratypes, probably labelled by some museum curator posteriorly to the syntypes designation.

\section{Diagnosis}

Body length $>20 \mathrm{~mm}$; male: tergite VII depressed at posterior fourth; connexival spines $1 / 5$ the medial length of tergite VIII (Fig. 7D).

\section{Redescription}

Uniformly apterous; body length: ô $21.7 \mathrm{~mm}$, क $22.4 \mathrm{~mm}$; distance between mesoacetabula: $\widehat{\sigma} 2.6 \mathrm{~mm}$, $q 2.7 \mathrm{~mm}$. Head: clypeus glabrous (as in Fig. 4B); vertex punctate (as in Fig. 4D); eyes $1.6-1.9 \times$ wider than interocular distance in dorsal view, ventral margin with conspicuous spines (as in Fig. 4F); article III of rostrum with small, sparsely distributed setae (as in Fig. $5 A$ ), 2.0-2.5 $\times$ longer than article IV; antennomere I $1.5 \times$ longer than antennomeres II and III combined; antennomere III $3 / 5$ the length of antennomere IV, the latter straight, 3/5of head width (as in Fig. 6B). Thorax: wings not developed (apterous); mesonotum 1.3-1.6× longer than pronotum and metanotum combined; anterodorsal region of prothoracic femur with 5-18 small spines; prothoracic tarsi 1.2-1.4 $\times$ longer than metathoracic tarsi; anterior region of metacetabula with a tuft of setae (as in Fig. $2 A$ ). Male: lateral margins of abdomen parallel or slightly diverging in dorsal view, tergite VII slightly wider than tergite II; sternites IV-VI lacking small spinules and concavities; tergite VII depressed posteriorly; connexival spines $1 / 5$ the length of tergite VIII (Fig. 7D); posterior margin of sternite VII rounded (Fig. 8D); lateral margins of tergite VIII parallel, apical and basal area slightly convergent; apex truncate to subacute (Fig. 7D); apex of pygophore rounded to subacute in ventral view; proctiger long, $\sim 2 \times$ longer than tergite VIII in dorsal view (Fig. $8 D$ ), basolateral processes short, directed sideways, $2.3-2.8 \times$ wider than long (Fig. 9D); phallus slightly rounded, more or less as wide as long, branches of sclerite approximately as wide as its confluence area (Fig. 2C). Female: posterior margin of mesonotum lacking large protuberances posteriorly (Fig. 2G); tergite VIII slender, apex rounded, gonocoxae lacking spines posteriorly (some specimens with a single spine); connexival spines $0.2-0.4 \mathrm{~mm}$ in length.

Colouration. Mostly yellow (Fig. $11 C, D$ ). Head: yellow in dorsal view (Fig. 14D); articles I and III of rostrum yellow, article III brown, sometimes lighter brown basally (Fig. 15D). Thorax: pronotum with black lateral stripes, wider than median yellow stripe; femora yellow; tibiae yellow with dark stripes medially, less conspicuous in darker specimens; mesonotum with black stripe, slightly narrower than yellow median stripe; mesopleuron and mesosternum yellow; metasternum with black stripe, slightly wider or narrower than median yellow stripe; metapleuron and metasternum yellow; meso- and metathoracic acetabula dorsolateral brown; mesothoracic femora with black stripes ventrally and dorsally, posterior region with or without discreet stripes. Abdomen: covered with light brown pubescence; tergites (I-VII) black with narrow median yellow stripe; connexiva and sternites (I-VII) yellow to brown; dorsal region of pleurites (I-VII) with a brown longitudinal stripe. Male: tergite VIII with longitudinal brown median spot, or entirely brown at the middle; sternite VIII and pygophore yellow. Female: tergite VIII and proctiger with longitudinal median brown stripe at the middle; gonocoxae yellow, with or without ventral black stripe.

\section{Comments}

This species superficially resembles $C$. hungerfordi and C. palmaris. It differs from those by its larger body size, yellow prothoracic tibia with black stripes, and tergite VII apically depressed in males. It can be readily distinguished from C. hungerfordi by the width of the black mesonotum stripes, which are as wide as the median yellow stripe (Fig. $11 C, D$ ). Males of $C$. regulus differ from males of $C$. palmaris by the basolateral processes of the proctiger (twice as long) (Fig. 9D) and rounded phallus, with sclerite branches as long as the width of its confluence area.

Examined specimens can be separated into two groups based on colour polymorphism and the variation in the shape of male genitalia. The first group includes yellow insects with a rounded pygophore in ventral view; tergite VIII rounded posteriorly; and apical margin of sternum VII rounded. The second group includes mostly brown insects that are slightly larger, with the posterior margin of pygophore and tergite VIII nearly acute, and apical margin of sternum VII rectangular. In the redescription of this species, Drake and Harris $(1930,1934)$ described a variation of 18.50 to $20 \mathrm{~mm}$ regarding the body size of the specimens. However, in this study all examined specimens have a body size larger than $20 \mathrm{~mm}$.

\section{linearis-group}

\section{Diagnosis}

Antennomere IV curved; ventral margin of eyes with inconspicuous spinules; abdominal sternites with numerous and agglomerated spinules; sternite VII emarginate; connexival spines long; proctiger short with long basolateral processes.

\section{Cylindrostethus bilobatus Kuitert, 1942}

Cylindrostethus bilobatus Kuitert, 1942: 137 [description]. Moreira et al., 2011b: 6. [checklist]. Floriano \& Cavichioli, 2013: 191 [key, illustration].

\section{Material examined}

Holotype male (SEMC). 'Bolivia, S.A $\backslash$ R. Beni Puerto $\backslash$ Salinas 11-37 A. M. Olalla (beige label)' ' $\widehat{o}$ (yellow label) 'HOLOTYPE $\backslash$ Cylindrostethus $\backslash$ bilobata $\backslash$ Det. L.C. Kuitert'; Allotype female (SEMC): 'Bolivia, S.A $\backslash$ R. Beni 
Puerto \Salinas 11-37 A. M. Olalla (beige label)' 'ALLOTYPE Cylindrostethus $\backslash$ bilobata $\backslash$ Det. L.C. Kuitert'.

Notes on types. The holotype is in a good state of preservation, except for a hole in the mesopleura. The allotype is poorly preserved; antennomeres III-IV, right prothoracic tarsus and left mesothoracic tibiae are missing, and the tibiae and apex of the article IV of rostrum are damaged.

\section{Diagnosis}

Male basolateral processes elongate, projected forwards (Fig. 8E), not visible dorsally, apex acute, not reaching the connexival spines (Figs $7 E, 8 E$ ); female with large processes on posterior margin of mesonotum (Fig. $2 F$ ).

\section{Redescription}

Uniformly apterous; body length: ô $13.9 \mathrm{~mm}$, o $16.2 \mathrm{~mm}$; distance between mesoacetabula: of $2.1 \mathrm{~mm}$, ㅇ $2.2 \mathrm{~mm}$. Head: clypeus densely pilose (as in Fig. $4 A$ ); vertex lacking punctations (as in Fig. 4C), eyes $1.3 \times$ as wide as interocular width in dorsal view; ventral margin showing inconspicuous spines (as in Fig. $4 E$ ); article III of rostrum $1.7 \times$ as long as article IV, setae covering $1 / 3$ of anteroventral and dorsal region (as in Fig. $5 B$ ); antennomere I $1.6 \times$ as long as antennomere II and III combined; antennomere III half as long as antennomere IV; antennomere IV $3 / 5 \times$ as long as head width, slightly curved (as in Fig. $6 A$ ). Thorax: mesonotum 1.9-2.1 $\times$ longer than pronotum and metanotum combined; anterodorsal region of prothoracic femora bearing fewer than 10 short spines; prothoracic tarsi slightly shorter than metathoracic tarsi; anterior region of metacetabula without a tuft of setae. Male: lateral margins of abdomen slightly divergent, towards posterior region, tergite VII $1.1 \times$ as wide as tergite II; sternites V-VI bearing small spinules at posterior margins; tergite VII not depressed on posterior fourth; connexival spines $3 / 5$ the length of tergite VIII; sternite VII bearing small, sparsely arranged spinules, lacking concavities, posterior margin conspicuously excavated at middle (Fig. 8E); lateral margins of basal III of tergite VIII slightly rounded, converging towards the anterior and posterior region, posterior margin slightly truncate (Fig. $7 E$ ); apex of pygophore rounded in ventral view (Fig. $8 E$ ); proctiger more or less equal in size to tergite VIII in dorsal view (Fig. $7 E$ ); basolateral processes elongate, directed forwards, apex acute, not visible in dorsal view (Fig. 7E), not reaching connexival spines (Fig. 8E). Female: posterior margin of mesonotum with large protuberances (Fig. 2F); apex of tergite VIII slightly rounded; posterior region of gonocoxae bearing spines; connexival spines $0.2 \mathrm{~mm}$ in length.

Colouration. Mostly brown (Fig. 12A, B). Head: yellow in dorsal view, frons brown, clypeus and vertex yellow (Fig. 14E); longitudinal dark brown stripe located medially, in ventral view; rostrum articles I and II yellow, article III black, gradually darkened towards the apex (Fig. 15E). Thorax: pronotum with median, light brown stripe; femora and basal III of tibia yellow; mesonotum and metanotum with brownish stripe; mesopleuron and metapleuron usually showing black dorsal stripe, brown in ventral view; mesosternum and metasternum yellow, covered with golden pubescence; meso- and metathoracic femora yellow, gradually darkened towards apex. Abdomen: covered with golden pubescence; tergites, pleurites and sternites (I-VII) brown; connexiva yellow. Male: pygophore and proctiger brown. Female: lateral margin of tergite VIII slightly lighter that central area; gonocoxae brown, slightly darker dorsally; proctiger brown.

\section{Comments}

This species superficially resembles C. bassleri, C. linearis, C. meloi and $C$. drakei, sp. nov.; however, males of C. bilobatus differ in the shape of the basolateral processes of the proctiger, which are longer and concealed in dorsal view, not reaching the connexival spines (Fig. $8 E$ ). The females differ from other congeneric species in having a protuberant posterior margin on the mesonotum (Fig. 2F).

\section{Cylindrostethus meloi Floriano \& Cavichioli, 2013}

Cylindrostethus bassleri, Moreira et al., 2011a: 272-273 [redescription, illustration] [misidentification].

Cylindrostethus meloi Floriano \& Cavichioli, 2013: 187-192 [description, key, illustration].

\section{Material examined}

Holotype male (INPA). 'Brasil: Amazonas $\backslash$ Ig. (Igarapé) Boiaçuzinho R. [Rio] Demeni - R. (Rio) Negro $\backslash 5-\mathrm{X}-1977$. Dellone' 'C. erythropus Inpa'. Paratype: three males, eight females (INPA): 'Brasil: Amazonas $\backslash$ Ig. [Igarapé] Boiaçuzinho $\backslash$ R. [Rio] Demeni - R. (Rio) Negro $\backslash 5$-X-1977. Dellone' 'C. erythropus - Inpa'; one male, one female [DZUP], remaning specimens at (INPA).

Other material examined. One female, one male (INPA): 'BR [Brasil]AM [Amazonas], Barcelos, Rio $\backslash$ Acará $\backslash 29-\mathrm{VII}-2009 \backslash$ PT 1006'. One male, four females (INPA): 'BR [Brasil] - AM [Amazonas] R. [Rio Solimões Jutaí igarapé, afluente do rio $\backslash$ Sapó' '276119 $-6679997^{\circ} \backslash 06-I X-2003 \backslash$ N.Hamada \& J. L. Nessimian' '2062'; four males, eight females (INPA): 'Brasil: Amazonas \Ig. [Igarapé] Boiaçuzinho $\backslash$ R. Demeni - R. (Rio) Negro $\backslash 5$-X1977. Dellone' 'C. erythropus - Inpa'; one female, one male (INPA): 'BR [Brasil]-AM [Amazonas], Barcelos, Rio \Acará $29-\mathrm{VII}-2009 \backslash \mathrm{PT}$ 1006'; one male (DZRJ): 'BR - AM R. (Rio) Solimões J. Itaí ifarapé (Igarapé), afluente do rio\Gapó' '2276119 - 66799976 -\ IX-2003\ Hamada \& Nessimian' '2062' PubMed.

\section{Diagnosis}

Mostly black (Figs $12 C, D, 14 F, 15 F$ ). Male proctiger with basolateral processes elongate, directed forwards (Fig. 9E), visible in dorsal view, apex acute, not reaching connexival spine (Figs $7 F, 8 F$ ).

\section{Comments}

Cylindrostethus meloi closely resembles C. bilobatus, C. bassleri, C. linearis and C. drakei, sp. nov.; however, differs from the latter three species in having the basolateral process of the proctiger with an acute apex (Fig. 9E). It can be distinguished from $C$. bilobatus by the elongated basolateral processes of proctiger in males, which are visible in dorsal view (Fig. $7 F$ ). Females of $C$. meloi differ from those of C. bilobulatus in lacking large protuberances on the posterior region of the mesonotum. This species was described by Floriano and Cavichioli (2013), but the authors did not specify the 

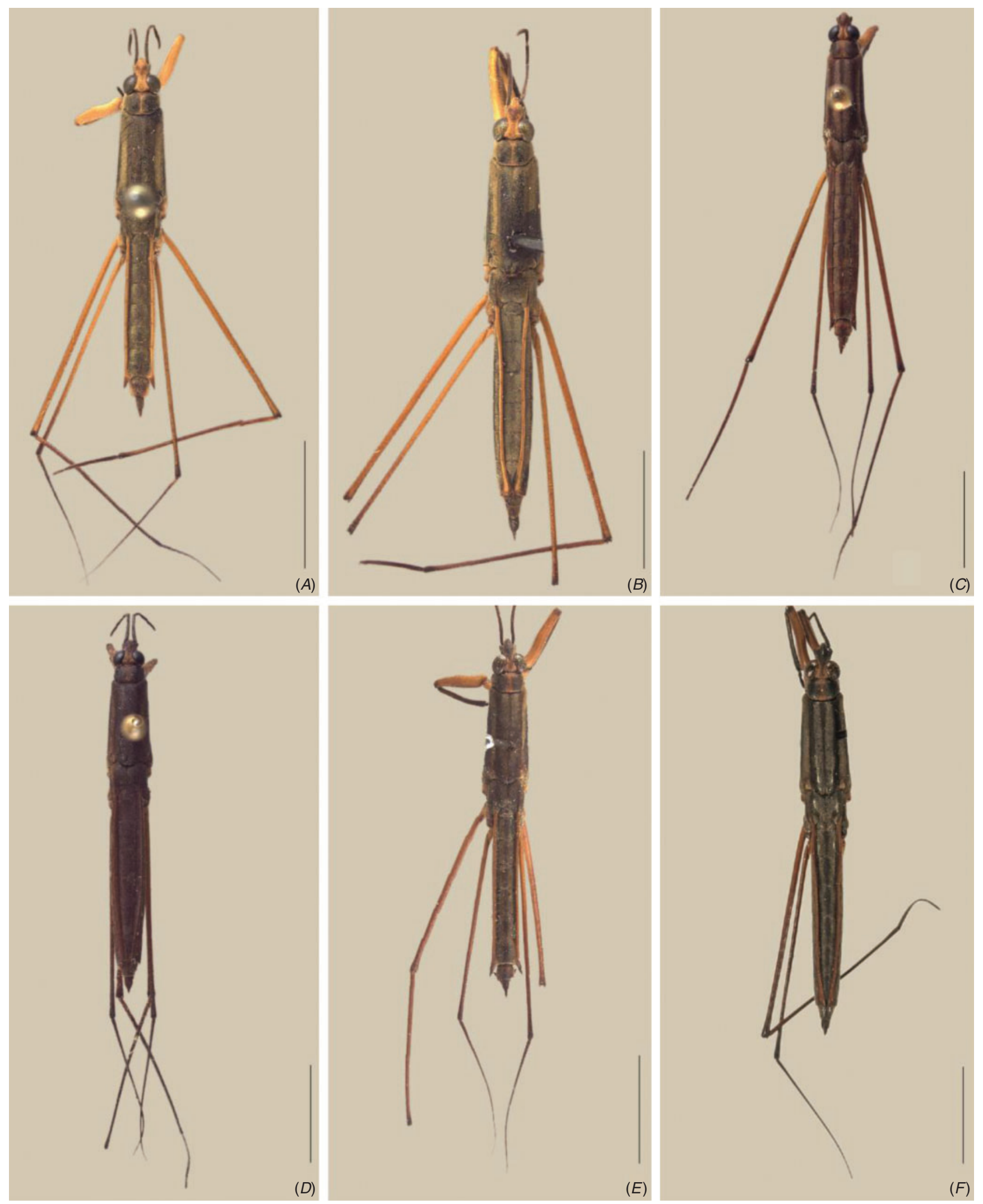

Fig. 12. Body, dorsal view. (A) Cylindrostethus bilobatus (male holotype);(B) C. bilobatus (female paratype); (C) C. meloi (male holotype); (D) C. meloi (female paratype); (E) C. bassleri (male paratype); (F) C. bassleri (female paratype) (both at AMNH). Scale bar $=5 \mathrm{~mm}$. 
etymology. The specific epithet was given in honour of Dr Alan Lane Melo.

\section{Cylindrostethus bassleri Drake, 1952}

Cylindrostethus bassleri Drake, 1952: 2-3 [description]; Floriano \& Cavichioli, 2013: 191 [key, illustration].

\section{Material examined}

Holotype male (AMNH). 'Rio Santiago, \Peru IX -4-24\F6139' 'Bassler Collection $\backslash$ AcC. 33591' '-Holotype- $\backslash$ Cylindrostethus $\backslash$ bassleri $\$ ô Drake' 'Holotype $\backslash$ Cylindrostethus $\backslash$ bassleri $\backslash$ Drake'.

Paratype male (AMNH). 'Paratype $\backslash$ by $C$. J. Drake $\backslash$ Cylindrostethus $\backslash$ bassleri (handwritten)' (red label) 'Rio Santiago \Peru IX-4-24\F 6134' (beige label) 'Cylindrostethus $\backslash$ bassleri D\&H' (beige label)' 'H. Bassler Collection $\backslash$ AcC. 33591' (beige label). (Photos sent by Ruth Salas.)

Paratype female (AMNH). 'Allotype $\backslash$ Cylindrostethus $\backslash$ bassleri Drake' (handwritten and red label) 'Allotipe $\backslash$ Cylindrostethus $\backslash$ bassleri Drake' (red label) 'Rio Santiago \Peru IX-2-24\F 6124' (beige label) 'H. Bassler Collection $\backslash$ AcC. 33591' (beige label).

Notes on types. The male paratype is damaged: antennomeres II-IV are absent. The left mesothoracic tarsus and right mesothoracic tibia are disassociated and glued separately on the label. The paratype female is lacking meso- and metathoracic legs.

\section{Diagnosis}

Males: basolateral processes elongate, projected forwards, visible in dorsal view; apex rounded, not concealed by connexival spines (Figs $7 G, 8 G$ ).

\section{Redescription}

Uniformly apterous; body length: $16.9 \mathrm{~mm}$; distance between mesoacetabula: o $2.3 \mathrm{~mm}$. Head: clypeus densely pilose (as in Fig. $4 A$ ); vertex lacking punctations (as in Fig. $4 C$ ); eyes $2 \times$ as wide as interocular width in dorsal view, ventral margin showing inconspicuous spines (as in Fig. 4E); article III of rostrum 1.7× longer than the IV, setae covering dorsal and $1 / 3$ of anteroventral region (as in Fig. $5 B$ ). Thorax: mesonotum $2.1 \times$ longer than pronotum and metanotum combined; anterodorsal region of prothoracic femora bearing fewer than 10 short spines; prothoracic tarsi slightly shorter than metathoracic tarsi; anterior region of metacetabula without a tuft of setae. Male: lateral margins of abdomen slightly divergent, towards posterior region, tergite VII $1.1 \times$ as wide as tergite II; sternites V and VI bearing small spinules located centrally; tergite VII flat; connexival spines $0.9 \times$ the median length of tergite VIII; sternite VII lacking spinules, with slightly oblique concavities at sides, posterior margin conspicuously excavated at middle (Fig. $8 G$ ); lateral margins of basal III of tergite VIII slightly rounded, posterior region nearly parallel, posterior margin more or less truncate (Fig. $7 G$ ); apex of pygophore rounded in ventral view (Fig. $8 G$ ); proctiger subequal in length to tergite VIII, in dorsal view; basolateral processes elongated, directed forwards, apex rounded, visible in dorsal view, not reaching connexival spines (Figs $7 G, 8 G$ ). Female: posterior margin of mesonotum lacking large protuberances (as in Fig. $2 G$ ); tergite VIII more or less quadrangular, apex slightly truncate; posterior region of gonocoxae lacking spines.
Colouration. Mostly dark brown (Fig. 12E, F). Head: eye margin yellow in dorsal view, brown longitudinal stripe extending towards anterior region; frontoclypeus black (Fig. 14G), with longitudinal dark brown stripe medially, in ventral view; rostrum articles I and II yellow, III black, gradually darkened towards apex (Fig. 15G). Thorax: pronotum with median light brown stripe; femora yellow; tibiae black; mesonotum and metanotum with black stripe delimited by dark brown stripes, mesopleuron and metapleuron often showing dorsal brown stripe; mesosternum and metasternum brown, covered with silver pubescence; mesoand metathoracic acetabulum and femora yellow, gradually darkened towards apex. Abdomen: covered with sparse golden pubescence; tergites, pleurites and sternites I-VII brown; connexiva yellow. Male: tergite VIII brown; basal area of sternite VIII and pygophore yellow, apical area of sternite VIII and proctiger brown. Female: lateral margin of tergite VIII lighter than central area; dorsal region of gonocoxae yellow, ventral region brown; brown proctiger.

\section{Comments}

This species closely resembles C. bilobatus, C. linearis, C. meloi and $C$. drakei, sp. nov. In C. bassleri, the basolateral processes of proctiger are elongated, but do not reach the connexival spines (Figs $7 G, 8 G$ ), unlike $C$. linearis and $C$. drakei, sp. nov. It can be also distinguished from C. bilobatus and C. meloi in having the apices of the basolateral processes on proctiger rounded (Figs $7 G, 8 G$ ).

\section{Cylindrostethus linearis (Erichson 1848)}

Hydrobates linearis Erichson, 1848: 614 [description]; Lethierry \& Severin, 1896: 63 [catalogued]

Cylindrostethus linearis Kirkaldy, 1897: 258 [taxonomy]; Kirkaldy \& Torre-Bueno, 1909: 210 [catalogue]. Schmidt, 1915: 362 [taxonomic notes]. Drake \& Harris, 1930: 238 [redescription]. Drake \& Harris, 1934: 220-221, 238-239 [redescribed, key, illustration]. Kuitert, 1942: 135-136 [key, taxonomic notes]. Nieser, 1970: 120-121, 135-137 [redescribed, illustrated]. Moreira et al., 2011a: 270, 274 [redescription, illustration]. Moreira et al., 2011b: 6 [checklist]; Floriano \& Cavichioli, 2013: 191 [key, illustration].

Hydrometra erythropus Herrich-Schäffer, 1850: 68-69, 923 [description, illustration], syn. nov.

Hydrobates erythropus Lethierry \& Severin, 1896: 63.

Cylindrostethus erythropus; Kirkaldy \& Torre-Bueno, 1909: 210 [catalogued]. Schimidt, 1915: 362 [taxonomic notes]. Drake \& Harris, 1934: 219-220, 238-239 [described, illustration]. Kuitert, 1942: 135-136 [key, taxonomic notes]. Nieser, 1970: 119-120, 135-137 [redescription, illustration]. Aristizábal, 2002: 81, 86-87 [key, redescription, illustration]. Moreira et al., 2011a: 270, 273-274 [key, redescription, illustration]. Moreira et al., 2011b: 6 [listed]; Floriano \& Cavichioli, 2013: 191 [key, illustration].

\section{Material examined}

Pictures taken by Marcela Monné. Syntype male (BMNH): 'Hydrobates linearis ed. $\backslash$ Krit. Guy. \Schomburgk (green label, manuscript)' 'Zool. Mus.। Berlin (beige label)' '3388 (brownish label)' 'Syn Typus (red label)'; one male syntype (BMNH): 'Brit. Guyana Schomburgk $\backslash$ N. 3388 (green label, manuscript)' 'Zool. Mus.। Berlin (beige label)' 'Syn Typus (red label)'; one female syntype (BMNH): 'Brit. Guyana $\backslash$ Schomburgk $\backslash$ N. 3388 (green label, manuscript)' 'Zool. Mus. I Berlin (beige label)' '3388 (brownish label)' 
'Syn Typus (red label)'; one male syntype (BMNH): 'H. linearis $\backslash$ Typ $\backslash$ Brit Guyana $\backslash$ Schomburgk (beige label, manuscript)' 'Cylindrostethus $\backslash$ linearis Erich (brown label, manuscript)' 'Zool. Mus \Berlin' 'Syn. Typus (red label)'; one female syntype (BMNH): 'H. linearis w. $\backslash$ typ $\backslash$ Brit Guyana $\backslash$ Schomburgk (beige label, manuscript)' 'Zoo. Mus $\backslash$ Berlin (beige label, manuscript' 'SynTypus (red label)'.

Other material examined. Two males, four females (INPA): '2.7611966799976 - \ IX-2003\ Hamada \& Nessimian' '20603 PubMed >'; four females, one male (INPA): 'BRASIL - AM \LAGO DE TEFÉ $\backslash$ RIO SOLIMÕES $\backslash$ 10-XII-76\COL - Eduardo' 'C. erythropus - Inpa' 'Cylindrostethus erythropus $\backslash$ (Herrich-Schäffer, 1850)\ $\operatorname{det}$ R. Sampaio1980'; four males, three females (INPA): 'BR - AM R. Solimões J.\Itaí Ifarapé [Igarapé], afluente do rio \Gapó' '206'; three males (DZRJ): 'BR - AM - R. Solimões,\Cadajás [Codajás], Urucuizinho, Lago A110 L IX-2003' 'PubMed Hamada \& Nessimian\2066'; one male (DZRJ): 'BR - AM, R. Solimões, \Cadajás [Codajás], Urucuizinho,\Lago Urucyu $\backslash 39196^{\circ}-6204738^{\circ}$ ' 'Lago A101 15-IX-2003\Hamada \& Nessimian 2064'; eight males, one female (DZUP): 'BR - AM - Manaus $\backslash$ R. Solimões $\backslash$ IG. (Igarapé) Pirapora VII-2011 Floriano'; one male (AMNH): 'PERU: Loreto: Iquitos, $\backslash$ Padre Island, 122., July 18, 1972\ R. T. \& J. C. Schuh' 'In quiet Waters along edge of river'; two males (AMNH): 'PERU:\ Loreto, Pucallpa\Yarinacocha\} 1 3 \text { July 1962 \W. T. Van Velzen'; four males, six } females (INPA): 'Rio Uraricoera. Ig. (Igarapé) Grande - RR Brasil 22-10-87. IQ. Granfinale' 'Cylindrostethus erythropus $\backslash$ (Herrich-Schäffer, 1850) \det. R. Sampaio 1850'; two females (INPA): 'BRASIL: AM I Careiro 20 -IX1976 B. Mascarenhas' 'C. erythropus - INPA' 'Cylindrostethus erythropus (Herrich-Schäffer-1850)\ det. R. Sampaio 1980)'; one male, one female (INPA): 'BRASIL: Amazonas $\backslash$ Manaus Rio Solimões $\backslash 20 \backslash X I \backslash 1975 \backslash$ B. Mascarenhas' 'C. erythropus - INPA' 'Cylindrostethus erythropus (Herrich-Schäffer-1850)\det. R. Sampaio 1980)'.
Notes on types. The three male syntypes are in a good state of preservation; one male syntype is lacking mesothoracic tarsi. Two female syntypes are in poor condition: one is lacking the right mesothoracic leg, and the other is lacking the right mesothoracic tibiae.

\section{Diagnosis}

Male: tergite VII 1.3-1.5× wider than tergite II (Fig. 9F); sternites V-VII with concavities on central area; basolateral processes of proctiger long, visible dorsally, apex rounded, directed forwards, slightly convergent towards posterior region, reaching the connexival spines (Figs $7 H, 8 H$ ), posterior width $1 / 2$ the size of anterior region (Fig. 9F).

\section{Redescription}

Apterous insects; body length: ô $14.9 \mathrm{~mm}$, $q 16.7 \mathrm{~mm}$; distance between mesoacetabula: ô $2 \mathrm{~mm}$, $+2.3 \mathrm{~mm}$. Head: clypeus densely pilose (Fig. 4A); vertex not punctate (Fig. 4C); eyes $1.2-1.6 \times$ wider than interocular distance, ventral margin with inconspicuous spines (Fig. 4E); article III of rostrum with setae covering $1 / 3$ of anteroventral and dorsal regions (Fig. $5 B$ ), article III $1.4-1.8 \times$ longer than article IV; antennomere I $1.3-1.5 \times$ longer than antennomere II and III combined; antennomere III half as long as antennomere IV; antennomere IV slightly curved, $\sim 4 / 5$ of head width (Fig. 6A). Thorax: mesonotum 2.2-2.4× longer than pronotum and metanotum combined; anterodorsal region of prothoracic femora with fewer than 10 short spines, prothoracic tarsi slightly shorter than metathoracic tarsi; anterior
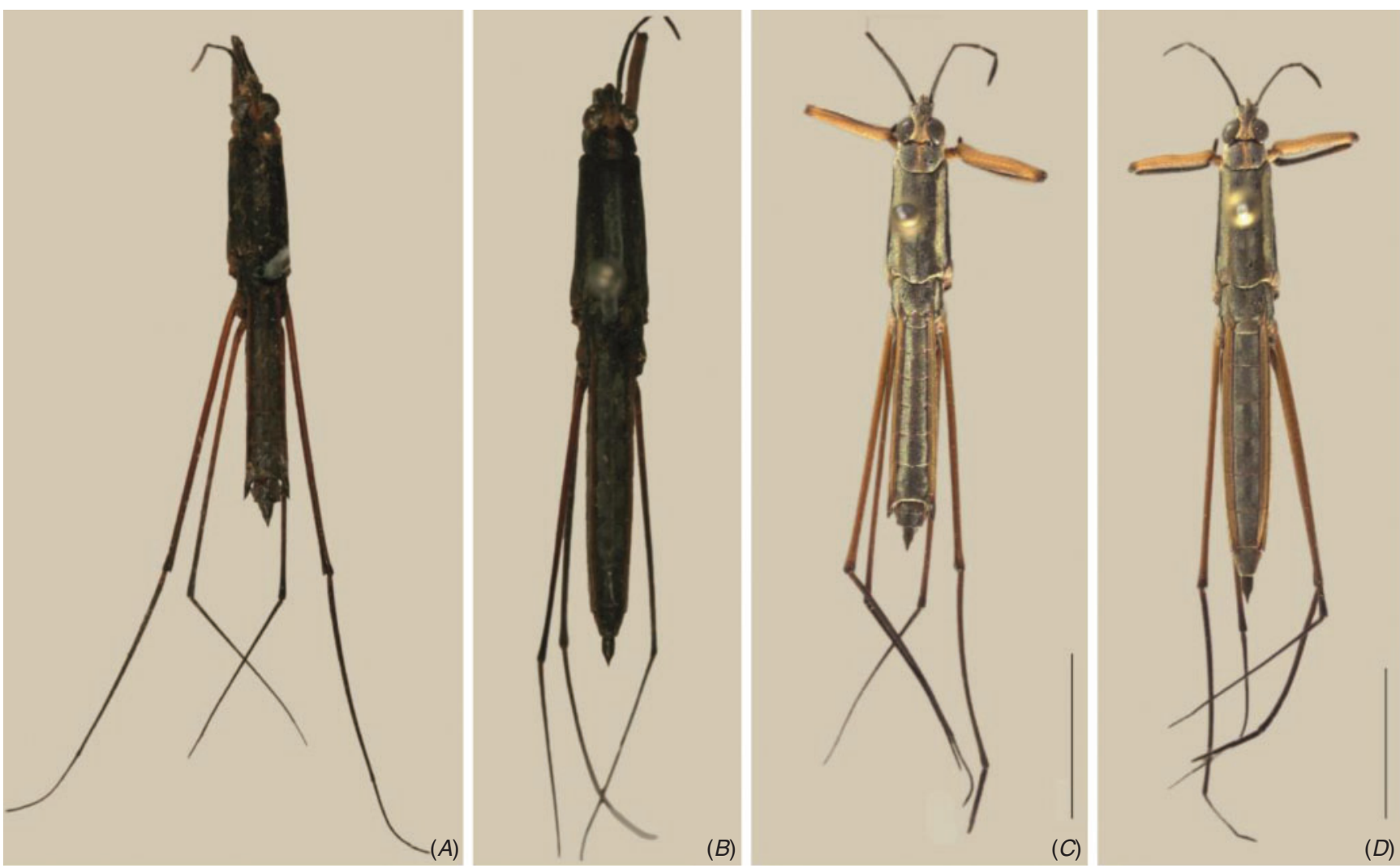

Fig. 13. Body, dorsal view. (A) Cylindrostethus linearis (male syntype) (image provided by Dra. Marcela Laura Monné Freire); (B) C. linearis (female syntype) (image provided by Dra. Marcela Laura Monné Freire); $(C) C$. drakei, sp. nov. (male holotype); $(D) C$. drakei, sp. nov. (female paratype). Scale bar=5 mm. 
region of metacetabula without a tuft of setae. Male: lateral margins of abdomen diverging towards the posterior region in dorsal view, tergite VII 1.3-1.5 $\times$ wider than tergite II; sternites IV-VI bearing small spinules located centrally; sternites V-VI with concavities at middle; tergite VII not depressed posteriorly; connexival spines $4 / 5$ the size of medial length of tergite VIII (Fig. 7H); sternite VII with conspicuous medial concavities, posterior margin conspicuously excavated medially (Fig. $8 H$ ); basal III of lateral margins of tergite VIII rounded, slightly divergent towards posterior region, posterior margin slightly truncate, median groove slightly marked; apex of pygophore rounded in ventral view (Fig. $8 H$ ); proctiger approximately as long as tergite VIII in dorsal view (Fig. 7H); basolateral processes long, apex rounded, directed forwards (Fig. $8 H$ ), visible dorsally, reaching connexival spines (Figs $7 \mathrm{H}, 8 \mathrm{H}$ ), slightly convergent towards posterior region, posterior width $1 / 2$ the size of anterior region (Fig. 9F); phallus elongated, $2 \times$ as long as wide, sclerite bifid basally, branches $2 \times$ longer than its area of confluence. Female: posterior margin of mesonotum lacking large protuberances (as in Fig. 2G); tergite VIII subquadranular, apex slightly truncate; gonocoxae with spines posteriorly; connexival spines $0.16-0.33 \mathrm{~mm}$ in length.

Colouration. Mostly dark brown or black (Fig. 13A, B). Head: eye margin yellow in dorsal view, dark longitudinal stripe enlarged towards anterior region; frontoclypeus black (Fig. 14H); longitudinal dark brown stripe ventrally; articles I and II of rostrum yellow, article III black, gradually darkened towards apex (Fig. 15H). Thorax: pronotum with median light brown stripe; prosternum, acetabula, coxae, trochanter and femora yellow; tibiae black; meso- and metanotum with median black stripe delimited by lighter stripes; mesopleuron and metapleuron with or without dorsal brown stripe, ventral area black; mesosternum and metasternum black, covered with silver pubescence; meso- and metathoracic acetabula yelow; meso-
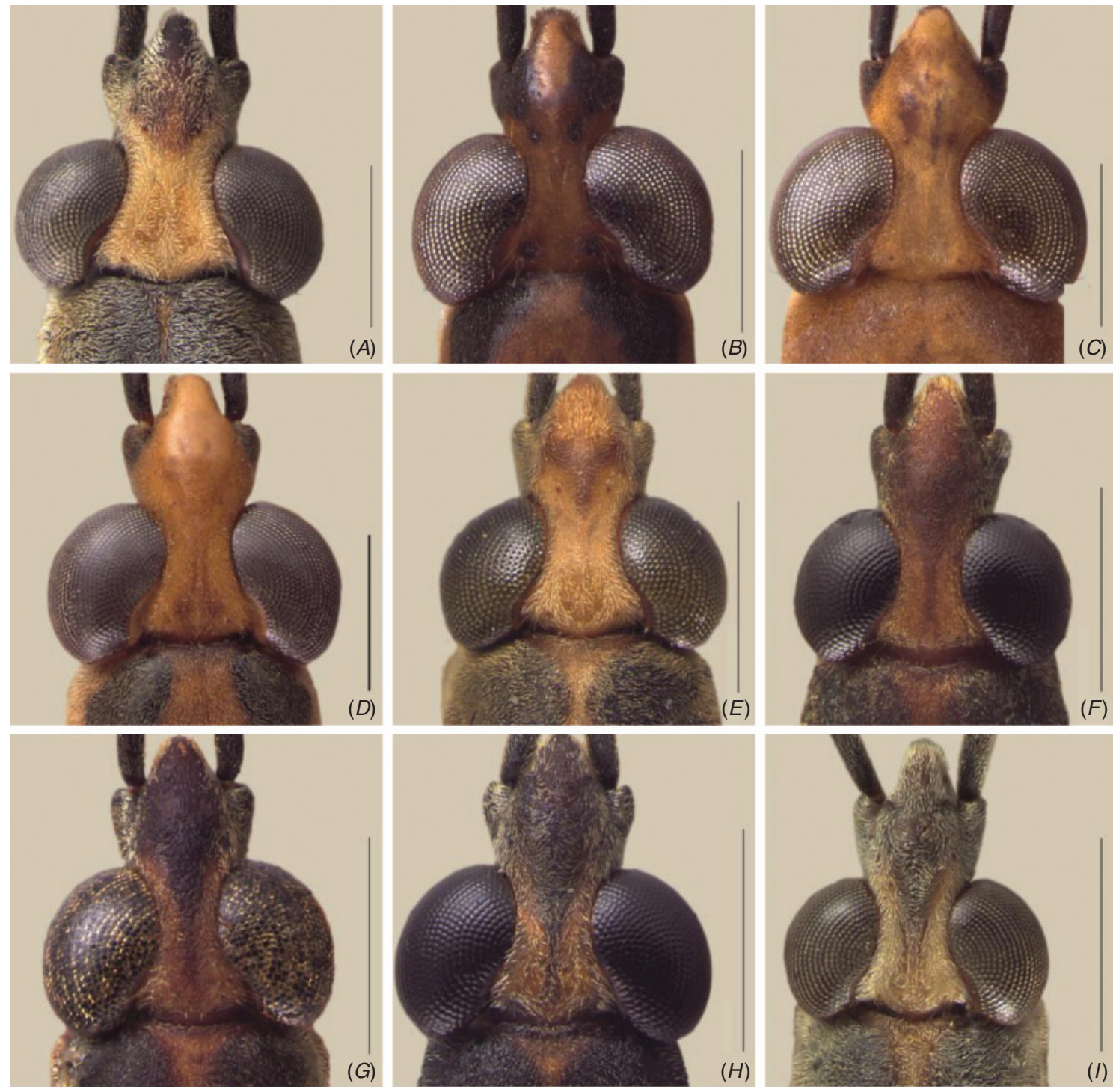

Fig. 14. Head, dorsal view. (A) Cylindrostethus podargus; (B) C. palmaris; $(C)$ C. hungerfordi; $(D)$ C. regulus; $($ E) C. bilobatus; (F) C. meloi; $(G)$ C. bassleri; $(H)$ C. linearis; $(I) C$. drakei, sp. nov. Scale bar $=1 \mathrm{~mm}$. 


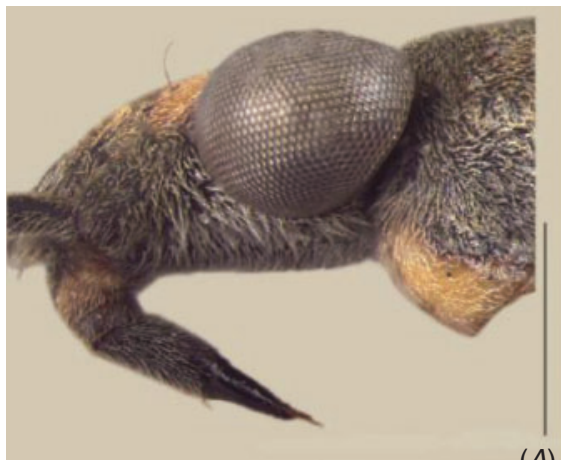

(A)

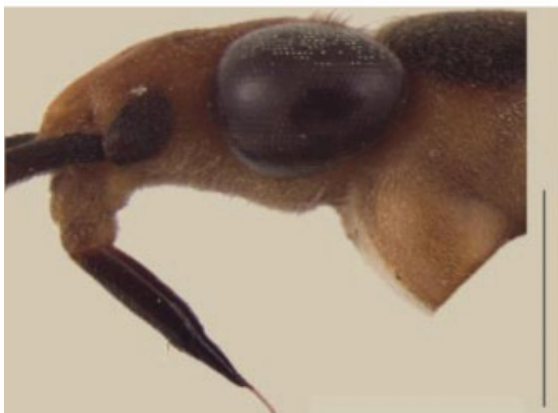

(D)

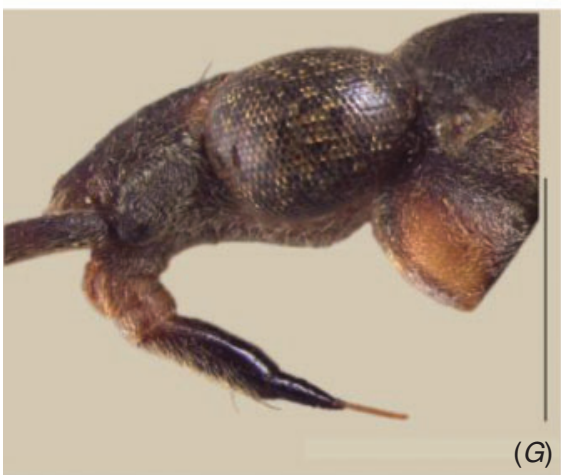

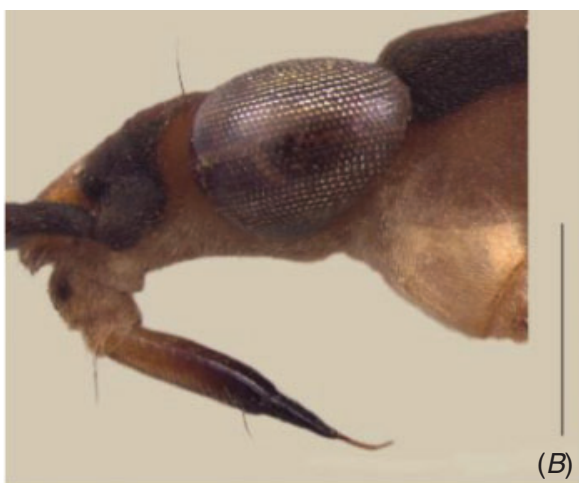
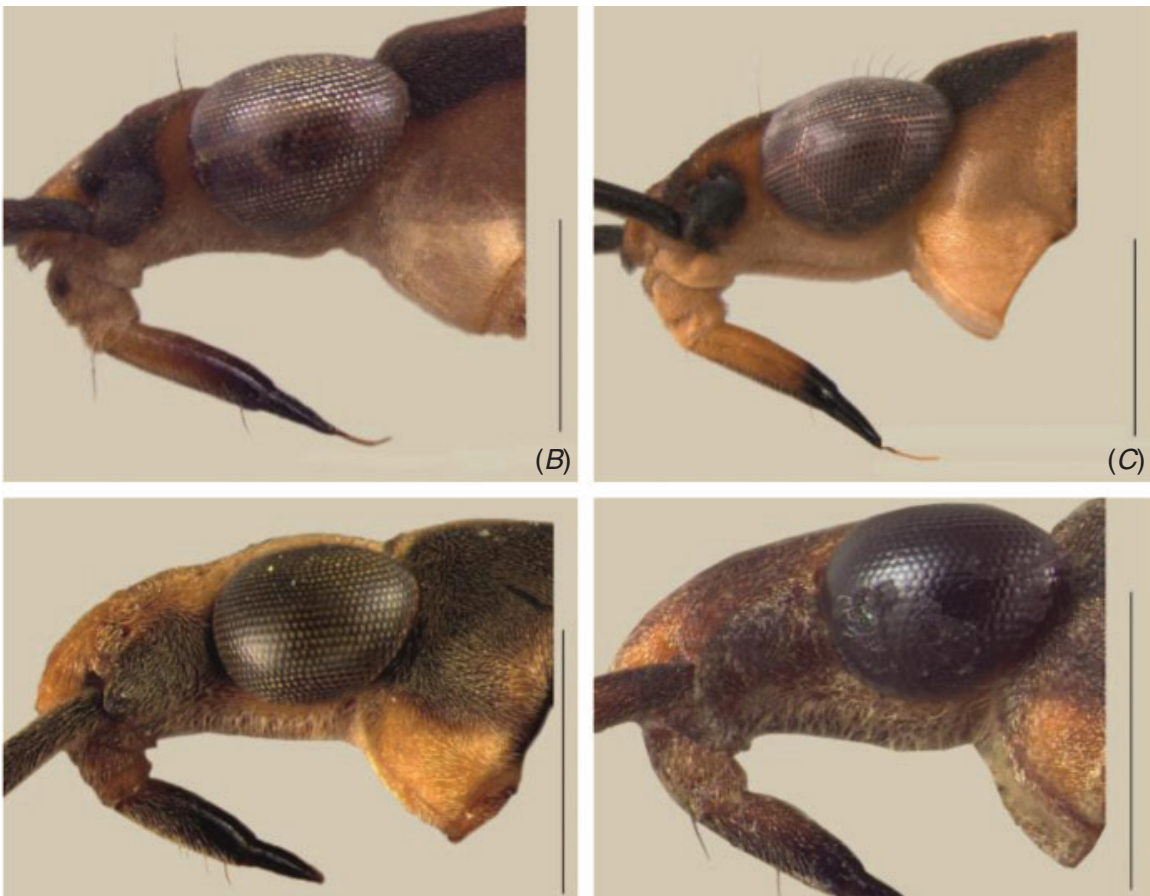

$(E)$
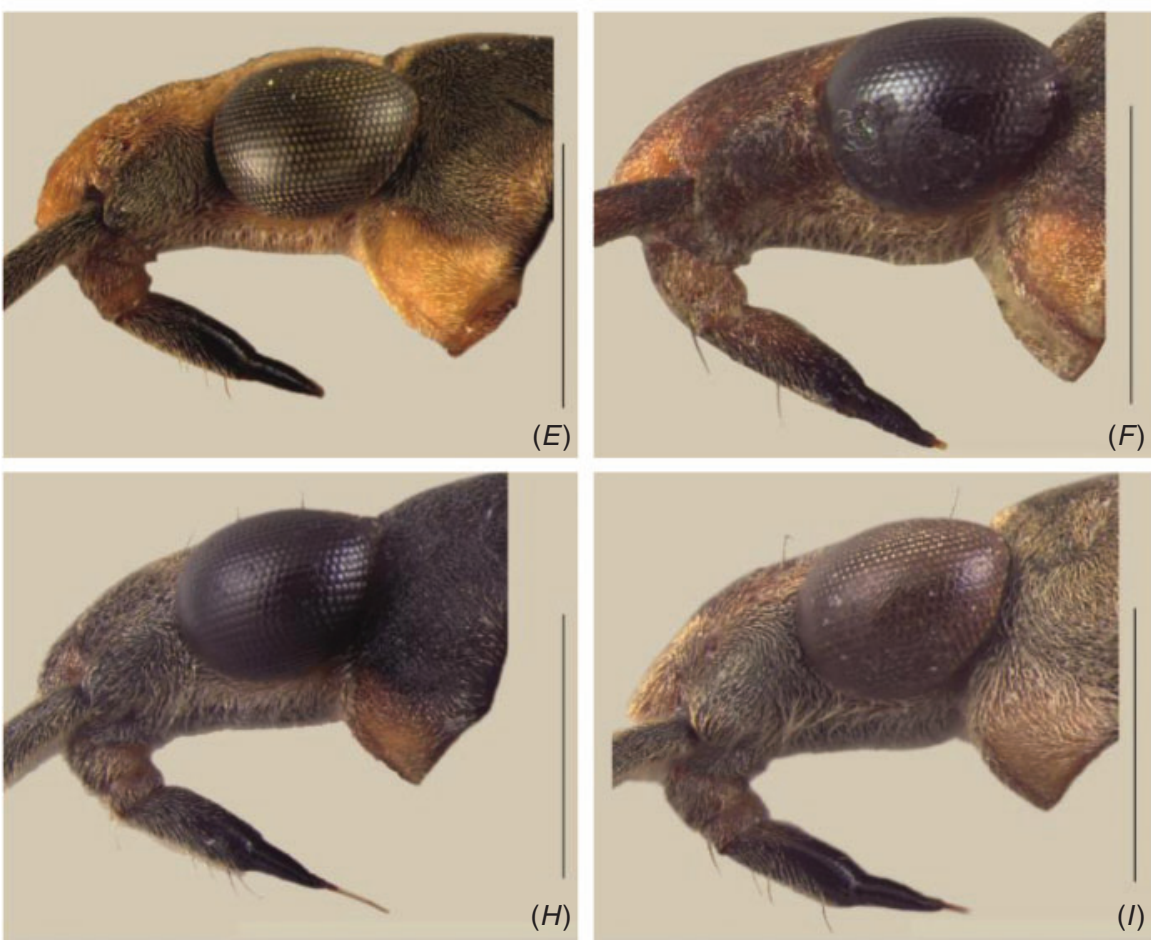

Fig. 15. Head, lateral view. (A) Cylindrostethus podargus; $(B)$ C. palmaris; $(C)$ C. hungerfordi; $(D)$ C. regulus; $(E)$ C. bilobatus; $(F)$ C. meloi; $(G)$ C. bassleri; (H) C. linearis; (I) C. drakei, sp. nov. Scale bar $=1 \mathrm{~mm}$.

and metathoracic femora yellow, gradually darkened towards apex. Abdomen: covered with sparse golden pubescence; tergites, pleurites and sternites (I-VII) brown or black; connexiva slightly lighter than tergites. Male: tergite VIII black, lateral and basal portions sometimes yellow; basal area of sternite VIII yellow, apical area black; pygophore and proctiger brown or black. Female: tergite VIII black, lateral margins yellow in some specimens; gonocoxae and proctiger brown or black, dorsal region of gonocoxae yellow in some specimens.

\section{Comments}

Cylindrostethus linearis superficially resembles C. bassleri, C. bilobatus, C. meloi and C. drakei, sp. nov. Males of C. linearis differ from C. bassleri, C. bilobatus and C. meloi in having the basolateral processes of the proctiger remarkably elongate, reaching the connexival spines, in ventral view
(Fig. $8 H$ ). Representatives of $C$. linearis differ from $C$. drakei, sp. nov. in their darker body colouration (Fig. 13A,B), in having the basolateral processes of the proctiger slightly convergent towards apex, with the apex $\sim 0.5 \times$ as wide as basal region (Fig. 9F), and sternites V-VII with central concavities.

After analysing illustrations, original descriptions and photos of syntypes of $C$. linearis (Fig. 16A-C), we concluded that specimens previously identified as $C$. erythropus, syn. nov. by Drake and Harris (1934), Nieser (1970) and Moreira et al. (2011a) are, in fact, representatives of $C$. linearis.

Drake and Harris (1934) redescribed $C$. linearis based on specimens of the type series; according to the drawings provided by the authors, the basolateral processes of the proctiger are curved with an acute apex. However, the shape of the basolateral processes in syntypes (as seen in photographs provided by Marcela Monné; Fig. 16A, C) differs from those in the illustrations. We did not examine the type series of 


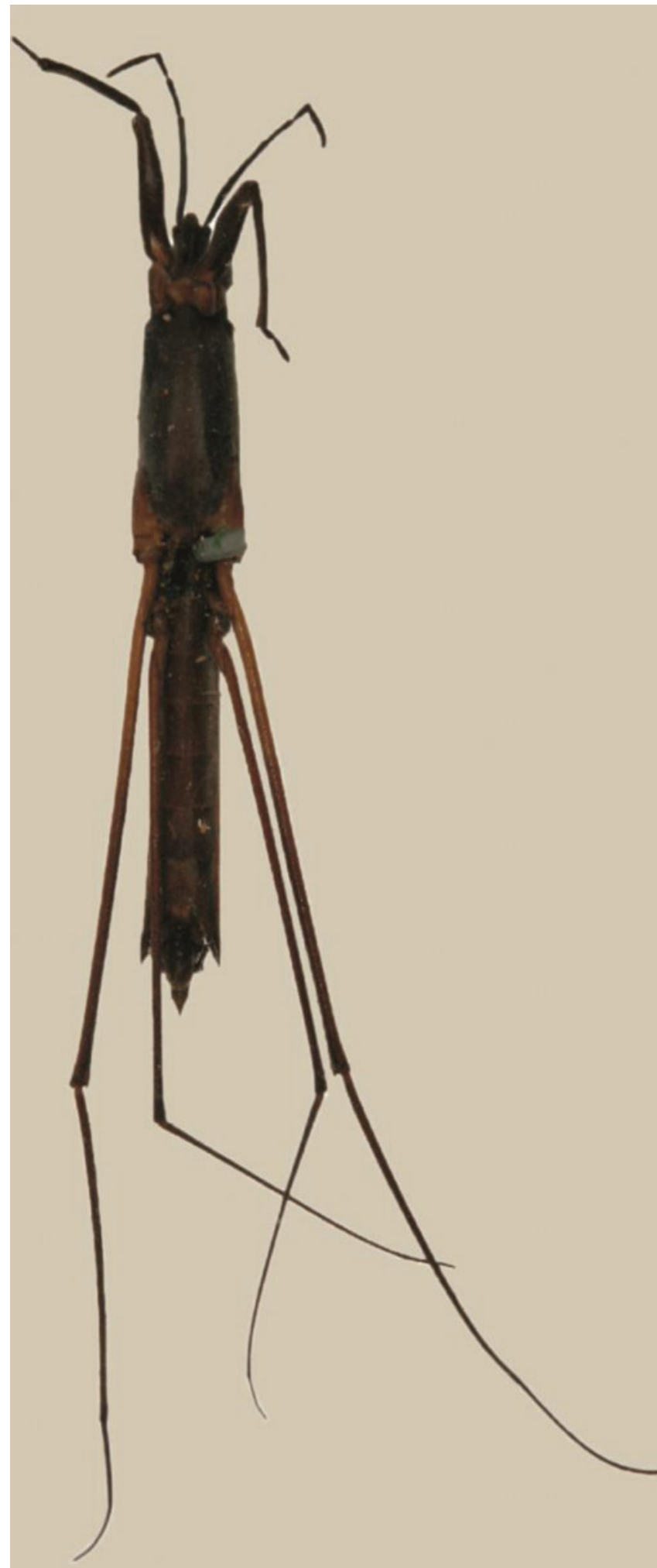

(A)
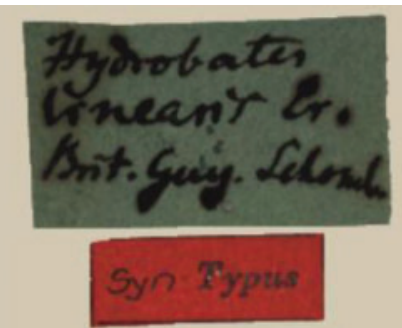

Zool. Mus. Berlin

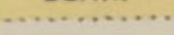

$\circ$

3388

(B)
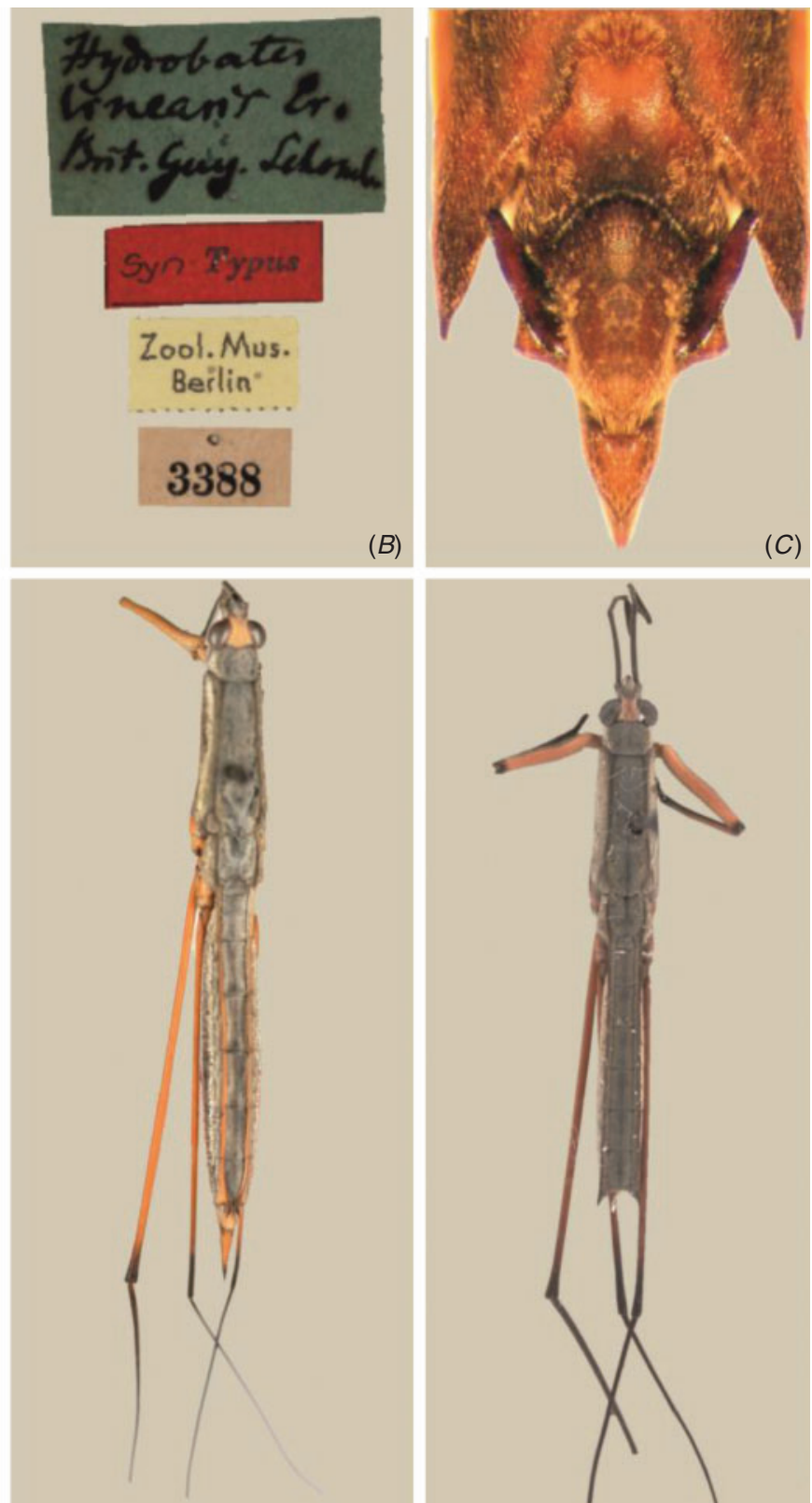

(D)

(E)

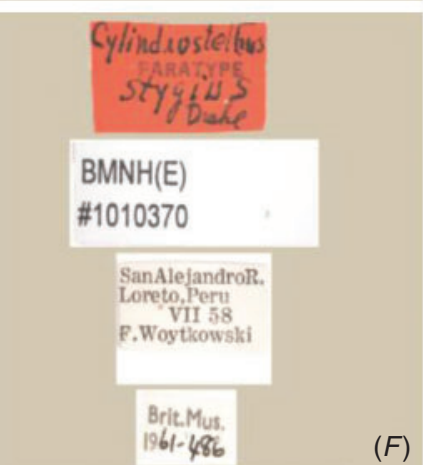

$(F)$

Fig. 16. Images of new junior synonyms. $(A, B)$ Cylindrostethus linearis (male syntype), ventral view, and corresponding labels, respectively; $(C) C$. linearis (syntype male), genitalia, ventral view; $(D) C$. stygius, syn. nov. (female paratype), dorsal view; $(E) C$. podargus (paratype male), dorsal view; $(F) C$. stygius, syn. nov., label of paratype; $(G) C$. podargus, label of paratype. (Image provided by Dra. Marcela Laura Monné Freire.) 
C. erythropus, syn. nov. According to Rider (1993), most of Herrich-Schäffer's types were lost in the First and Second world wars. The illustrations of C. erythropus, syn. nov. provided by Herrich-Schäffer (1850) indicate that the lateral margins of the abdomen are strongly divergent, in the same fashion as the syntypes of $C$. linearis. Therefore, $C$. erythropus, syn. nov. is here proposed as a synonym of $C$. linearis.

\section{Ecological notes}

In a recent field expedition, specimens of $C$. linearis were obtained from a stream in Amazonas State, Manaus, Brazil (the Pirapora River). The insects were found in groups, usually in shady, deep water bodies with moderate flow; the river was $\sim 10 \mathrm{~m}$ wide.

\section{Cylindrostethus drakei, sp. nov.}

Cylindrostethus linearis Drake \& Harris, 1934: 219, 220-221, 238-239 (misidentification). Nieser, 1970: 120-121, 135, 137 (misidentification). Moreira et al., 2011a: 270, 273, 274 (misidentification).

http://zoobank.org/urn:1sid:zoobank.org:act:1305BE19-5CE4-4C5A-9D 2F-441D7E9849E2

\section{Material examined}

Holotype male (MPEG). 'Brasil Rondônia Porto Velho\Rio Madeira 23-V-1984' 'Brasil Rondônia\ Marclo Zanuto'. Paratype (MPEG) (four males, one female): same data as the holotype.

Other material examined. Eight males, 13 females (UFRJ): 'Brasil, AM, R. Solimões, COdojás, $\backslash$ Urucurizinho, Lago Urucuri $\backslash-39196^{\circ}-6204738^{\circ} \backslash$ Lago. A10 L 15 -IX-2003 \N. Hamada \& J. L. Nessimian'. One male (INPA): 'Coleção \Campos Seabra' 'Col. Campos SEABRA\Itacoatiara Amazonas BRAZIL 15-VI-952 Orlando M. Rego'; two males, three females (INPA): 'BR - AM - Rio Solimões \Coari, Monte das Oliveiras $\ 389341$ - 6336261〉 A08 L 12-IX-2003' 'Hamada \& Nessimian $\backslash 2411$ '; one male (DZRJ): 'BR AM - R. Solimões \Cadajás [Codajás], Urucurizinho lago Urucyu $\backslash 39196^{\circ}$ 6204738 ' 'Lago A101 15-IX-2003\Hamada \& Nessimian $\backslash 2064$ '; one male (INPA): 'BR - AM - Solimões, $\backslash$ Coari, Monte das $\backslash$ Oliveiras' ' $389341^{\circ}$ PubMed -6335261 $\backslash$ Lago A08 L 12-IX-2003\ Hamada \& Nessimian'; Five males, five females (AMNH): 'PERU: Loreto: Iquitos, $\backslash$ Padre Island, 122 m., July 18, 1972 R.T. \& J. C. Schuh' 'In quiet Waters along $\backslash$ edge of river'; five males, two females (AMNH): 'PERU: Loreto: Iquitos, Amazon River, 120 m., July $181972 \backslash$ R.T. \& J.C. Schuh' 'Cylindrostethus $\backslash$ regulus (White) $\backslash$ det. Calabrese'.

\section{Diagnosis}

Male: tergite VII 1.1-1.2× wider than tergite II; sternite VII with concavities at each side; proctiger with pair of basolateral processes, strongly converging towards posterior region, reaching and overlapping connexival spines (Figs 7I, 8I); posterior region $3 / 10$ the width of anterior region (Fig. $9 G$ ), visible dorsally.

\section{Description}

Apterous insects; body length: ô $14.2 \mathrm{~mm}, q 16.2 \mathrm{~mm}$; distance between mesoacetabula: ô $2.0 \mathrm{~mm}$; $+2.2 \mathrm{~mm}$. Head: clypeus densely pilose (as in Fig. 4A); vertex not punctate (as in Fig. 4C); eyes $1.4 \times$ wider than interocular distance; ventral margin with inconspicuous spines (as in Fig. 4E); 1/3 of anteroventral and dorsal region of article III of rostrum covered with setae (as in Fig. $5 B$ ), article III of rostrum $1.5-1.7 \times$ longer than article IV; antennomere I $1.5 \times$ longer than antennomeres II and III combined; antennomere III $0.5 \times$ as long as antennomere IV, antennomere IV slightly curved, $7 / 10$ the width of head (as in Fig. 6A). Thorax: mesonotum 1.9-2.1 $\times$ longer than pronotum and metanotum combined; anterodorsal region of prothoracic femora bearing fewer than 10 minute spines; prothoracic tarsi slightly shorter than metathoracic tarsi; anterior region of metacetabula without a tuft of setae. Male: lateral margins slightly diverging from the posterior region in dorsal view, tergite VII 1.1-1.2 $\times$ wider than tergite II; posterior margin of sternites IV-VI bearing minute spines located centally; tergite VII not depressed posteriorly; connexival spines $0.8-0.9 \times$ smaller than tergite VIII (Fig. 7I); lateral region of sternite VII with conspicuous concavities (Fig. 8I); lateral margins of tergite VIII slightly rounded at basal III, diverging from posterior region, posterior margin slightly truncate, with or without slightly marked median groove (Fig. 7I); apex of pygophore rounded apex ventrally (Fig. 8I); proctiger approximately as long as tergite VIII (Fig. 7I); basolateral processes long, apex rounded, projected forwards (Fig. 9G), visible in dorsal view, reaching connexival spines (Figs $7 I, 8 I$ ), strongly converging towards posterior region, posterior region $3 / 10$ the width of anterior region (Fig. $9 G$ ); phallus slender, $2 \times$ as long as wide, sclerite bifid basally, branches $2 \times$ longer than its area of confluence; apex slightly rounded (as in Fig. 2C). Female: posterior margin of mesonotum lacking large protuberances (Fig. 2G); tergite VIII subquandrangular, apex slightly truncate; posterior region of gonocoxae with spines; connexival spines $0.3-0.4 \mathrm{~mm}$ in length.

Colouration. Mostly brown or dark brown (Fig. $13 C, D$ ). Head: eye margin yellow in dorsal view, brown longitudinal stripes extended and enlarged towards apex of frontoclypeus, black (Fig. 14I); longitudinal dark brown stripes medially, in ventral view; articles I and III of rostrum yellow, article III black, gradually darkened towards apex (Fig. 15I). Thorax: pronotum with median light brown groove; femora yellow; tibiae black; meso- and metanotum with black stripe delimited medially by brown stripes; mesopleuron and metapleuron with brown dorsal stripe, ventral region brown to black; mesosternum and metasternum brown to black, covered with greyish pubescence; meso- and metathoracic acetabula yellow, gradually darkened towards apex. Abdomen covered with greyish pubescence; tergites, pleurites and sternites (I-VII) brown to black; connexiva yellow. Male: tergite VIII black, sometimes yellow at base and sides; pygophore and proctiger brown or black. Female: sides of tergite VIII lighter than middle; gonocoxae and proctiger black, dorsal region of gonocoxae slightly lighter.

\section{Comments}

This species superficially resembles C. bassleri, C. bilobatus, C. linearis and $C$. meloi. The males differ from those of C. bassleri, C. meloi and C. bilobatus in the long basolateral processes of the proctiger, which overlap the connexival spines (Fig. 9G). This species is also morphologically similar to C. linearis, but differs in the following features: lighter colouration (Fig. 13C,D), basolateral processes of proctiger strongly convergent apically, apical region $3 / 10$ the width of 
anterior region (Fig. 9G), sternites V-VII with oblique concavities at sides. Although the type specimens here listed were previously identified as $C$. linearis by several authors (also refer to comments in $C$. linearis), we consider these specimens to represent our new species.

\section{Ecological notes}

This species can be found in rivers (Drake and Harris 1934). Moreira et al. (2011a) observed this species in ponds. It appears to occur in sympatry with $C$. linearis.

\section{Etymology}

This species is named in honour of Carl J. Drake, in recognition of his important contributions to hemipteran systematics.

\section{Acknowledgements}

The authors thank the invaluable help of several curators and colleagues who granted access to insect collections, and provided photographs of type specimens: Augusto Loureiro Henriques, Bärbel Stock, Caroline S. Chaboo, Dan Polhemus, Fredy Molano-Rendón, Irina Morales-Castaño, Jorge L. Nessimian, Katie Kramer, Ruth Salas, Randall Schuh, Orlando T. Silveira, Thomas J. Henry, Marcela Monné, José Albertino Rafael, Ruth Salas, Ruth L. F. Keppler and Neusa Hamada. We are also indebted to Felipe F. F. Moreira, for providing and clarifying doubts. We thank the entomology graduate program at the Federal University of Paraná for providing institutional support for this study. We also thank Thomas J. Henry, Robert Robbins and Kim Ribeiro Barão for his valuable comments on the manuscript and the anonymous reviewers for their useful and constructive comments. This research was funded by CAPES, FAPESP [grant no. 2013/16367-0] (C. F. B. Floriano), and CNPq [grants no. 303127/2010-4, 150163/2013-4, R. R. Cavichioli and A. Paladini, respectively]. This is the contribution number 1925 of the Department of Zoology of the Universidade Federal do Paraná.

\section{References}

Andersen, N. M. (1975). The Limnogonus and Neogerris of the Old World with character analysis and a reclassification of the Gerridae (Hemiptera: Gerridae). Entomologica Scandinavica 7(Suppl.), 1-96.

Andersen, N. M. (1982). The semiaquatic bugs (Hemiptera, Gerromorpha) phylogeny, adaptations, biogeography and classification. Entomonograph 3, $1-455$.

Aristizábal, H. G. (2002). 'Los Hemípteros de la Película Superficial del Agua em Colombia.' (Academia Colombiana de Ciencias Exactas, Físicas y Naturales: Bogotá, Colombia.)

Bremer, K. (1994). Branch support and tree stability. Cladistics 10, 295-304. doi:10.1111/j.1096-0031.1994.tb00179.x

Buzzetti, F. M. (2006). The genus Potamobates Champion in Ecuador, with description of P. shuarn. sp. (Hemiptera: Gerridae). Zootaxa 1306, 51-56.

Cognato, A. I. (1998). A new Potamobates Champion species (Heteroptera: Gerridae) from Ecuador with new distribution records for $P$. williamsi Hungerford. Insecta Mundi 12, 17-23.

Damgaard, J. (2008). Phylogeny of the semiaquatic bugs (HemipteraHeteroptera. Gerromorpha). Insect Systematics \& Evolution 39(4), 431-460. doi:10.1163/187631208788784264

Damgaard, J., Andersen, N. M., and Meier, R. (2005). Combining molecular and morphological analyses of water strider phylogeny (HemipteraHeteroptera, Gerromorpha): effects of alignment and taxon sampling. Systematic Entomology 30, 289-309. doi:10.1111/j.1365-3113.2004. 00275.x
Drake, C. J. (1952). The American species of Cylindrostethus Mayr (Hemiptera, Gerridae). American Museum Novitates 1579, 1-3.

Drake, C. J. (1958). Two new species of water-striders from Peru (Hemiptera: Gerridae). Bulletin of the Brooklyn Entomological Society 53, 109-111.

Drake, C. J. (1961). A new Cylindrostethus from Peru (Hemiptera: Gerridae). Proceedings of the Biological Society of Washington 74, 65-66.

Drake, C. J., and Harris, H. M. (1930). Notes on some South American Gerridae (Hemiptera). Annals of the Carnegie Museum 19 (4), 235-239.

Drake, C. J., and Harris, H. M. (1934). The Gerrinae of the western hemisphere (Hemiptera). Annals of the Carnegie Museum 23, 179-241.

Drake, C. J., and Harris, H. M. (1935). Notes on American gerrids (Hemiptera). Arkiv för Zoologi 28B(2), 1-4.

Erichson, W. F. (1848). Insecten. In 'Reisen in Britisch-Guiana in den Jahren 1849-1844'. (Ed. Shomburgk.) pp. 553-617. (J. J. Weber: Leipzig, Germany.)

Esaki, T. (1926). On some species of Potamobates (Hemiptera: Gerridae). Annales Musei Nationalis Hungarici 23, 251-257.

Fieber, F. X. (1861). 'Die Europaischen Hemiptera. Halbfluger. (Rhynchota: Heteroptera).' (Carn Gerold's Sohn: Wien, Austria.)

Floriano, C. F. B., and Cavichioli, R. R. (2013). A new species of Cylindrostethus Mayr (Hemiptera, Gerromorpha, Gerridae) for the Neotropical region, with an identification key for the species of Group 1 sensu Drake 1952. Zootaxa 3702(2), 187-192. doi:10.11646/zootaxa. 3702.2.7

Goloboff, P. A. (1993). Estimating character weights during tree search. Cladistics 9, 83-91. doi:10.1111/j.1096-0031.1993.tb00209.x

Goloboff, P. A., Farris, J. S., and Nixon, K. C. (2008). TNT, a free program for phylogenetic analysis. Cladistics 24, 774-786. doi:10.1111/j.1096-0031. 2008.00217.x

Herrich-Schäffer, G. A. W. (1831-1853). 'Die Wanzenartigen Insecten. Getreu nach der Natur Abgebildet und Beschrieben.' (Nürnberg, Germany.)

Hungerford, H. B. (1936). A new Potamobates from Peru, S. A. (Hemiptera, Gerridae). Bulletin of the Broobkyn Entomological Society 31, 178-180.

Hungerford, H. B., and Matsuda, R. (1960). Morphology, evolution and a classification of the Gerridae (Hemiptera-Heteroptera). The University of Kansas Science Bulletin 41(2), 25-632.

Hungerford, H. B., and Matsuda, R. (1962). The genus Cylindrostethus Fieber from the eastern hemisphere. The University of Kansas Science Bulletin 43(3), 83-111.

Hynes, H. B. N. (1948). Notes on the aquatic Hemiptera-Heteroptera of Trinidad and Tobago, B.W.I., with a description of a new species of Martarega B. White (Notonectidae). Transactions of the Royal Entomological Society of London 99(10), 341-360. doi:10.1111/j.13 65-2311.1948.tb01225.x

ICZN (2000). International Code of Zoological Nomenclature, 4th edn. The International Trust for Zoological Nomenclature c/o. The Natural History Museum, London, U.K. 305.

Kirkaldym, G. W. (1897). Synonymic notes on aquatic Rhynchota. The Entomologist 30, 258-260.

Kirkaldy, G. W. (1899). Aquatic Rhynchota in the collections of the Royal Museum of Belgium. Notes and descriptions. Annales de la Société Entomologique del Belgique 1899, 505-510.

Kirkaldy, G. W., and Torre-Bueno, J. R. (1909). A catalogue of American aquatic and semiaquatic Hemiptera. Proceedings of the Entomological Society of Washington 10, 173-213.

Kort-Gommers, M., and Nieser, N. (1969). Records of Antillean waterstriders (Heteroptera). Studies on the Fauna of Curaçao and Other Caribbean Islands 30(112), 72-87.

Kuitert, L. C. (1942). Gerrinae in University of Kansas Collections. The University of Kansas Science Bulletin 28(7), 113-143. 
Lethierry, L., and Severin, G. (1896). 'Catalogue Général des Hémiptères'. (L'Académie Royale de Belgique: Bruxelles, Belgium).

Mayr, G. L. (1865). Diagnosen neuer Hemipteren. II. Verhandlungen der Zoologisch-Botanischen Gesellschaft Wien 15, 430-446.

Mazzucconi, S. A., Ruf, M. L., and Bachmann, A. O. (2008). Gerromorpha y Nepomorpha (Insecta: Heteroptera) del Parque Provincial Salto Encantado del Valle del Cuña Pirú, Provincia de Misiones, Argentina. Lundiana 9(1), 57-66.

Morales, C. I. T., Molano, R. F., and Castro, V. M. I. (2013). Nueva espécie de Potamobates Champion, 1898 (Insecta: Hemiptera: Heteroptera: Gerridae: Cylindrostethinae) Del Pacífico Colombiano. Boletín Científico Centro de Museos, Museo de Historia Natural 17, 189-195.

Moreira, F. F. F., Alecrim, V. P., and Ribeiro, J. R. I. (2011a). Identification key to the Gerridae (Insecta: Heteroptera: Gerromorpha) from the Amazon River floodplain, Brazil, with new records for the Brazilian Amazon. Zoologia 28(2), 269-279. doi:10.1590/S1984-46702011000200018

Moreira, F. F. F., Barbosa, J. F., Ribeiro, J. R. I., and Alecrim, V. P. (2011b). Checklist and distribution of semiaquatic and aquatic Heteroptera (Gerromorpha and Nepomorpha) occurring in Brazil. Zootaxa 2958, $1-74$.

Nieser, N. (1970). Gerridae of Suriname and the Amazon. Studies Fauna Suriname 47, 94-138.

Nieser, N., and Melo, A. L. (1997). 'Os Heterópteros Aquáticos de Minas Gerais - Guia Introdutório com Chave de Identificação para as Espécies de Nepomorpha e Gerromorpha.' (UFMG: Belo Horizonte, Brazil.)

Nixon, K. C. (1999-2002). Winclada ver 1.0000 Published by the author, Ithaca, NY, USA.

Padilla-Gil, D. M., and Damgaard, J. (2011). A new species of Potamobates Champion from Colombia with a re-analysis of phylogenetic relationships (Hemiptera: Gerridae). Zootaxa 2879, 41-49.

Pereira, D. L. V., Melo, A. L., and Hamada, N. (2007). Chaves de identificação para famílias e gêneros de Gerromorpha e Nepomorpha (Insecta:
Heteroptera) na Amazônia Central. Neotropical Entomology 36(2), 210-228. doi:10.1590/S1519-566X2007000200007

Polhemus, D. A. (1994). Taxonomy, phylogeny, and zoogeography of the genus Cylindrostethus Fieber in the Paleotropical region (Heteroptera: Gerridae). Bishop Museum Occasional Papers 38, 1-34.

Polhemus, J. T., and Polhemus, D. A. (1995). A phylogenetic review of the Potamobates fauna of Colombia (Heteroptera: Gerridae), with descriptions of three new species. Proceedings of the Entomological Society of Washington 97(2), 350-372.

Polhemus, J. T., and Polhemus, D. A. (2008). Global diversity of true bugs (Heteroptera; Insecta) in freshwater. Hydrobiologia 595, 379-391. doi:10.1007/s10750-007-9033-1

Rider, D. A. (1993). Discovery of the type of Platistus spiniceps (HerrichSchäffer, 1840) and Agroecus scabricornis (Herrich-Schäffer, 1844), with a redescription of Platistus and its only included species, P. spiniceps (Heteroptera: Pentatomidae). Journal of the New York Entomological Society 101(3), 417-423.

Roback, S. S. (1966). The Catherwood Foundation Peruvian-Amazon Expedition VIII - Aquatic Hemiptera-Heteroptera. Monographs Academy of Natural Sciences of Philadelphia 14, 211-215.

Schmidt, E. (1915). Zur Kenntnis der Genera Saceseurus Breddin und Cylindrostethus Fieber (Hemiptera Heteroptera). Stettiner Entomologische Zeitung 76, 359-364.

White, F. B. (1879a). Descriptions of new Hemiptera. (I). Journal of the Linnean Society of London. Zoology 14, 482-489.

White, F. B. (1879b). List of the Hemiptera collected in the Amazons by Prof. J. W. H. Trail, M. A., M. D., in the years 1873-1875, PubMed with descriptions of the new species. The Transactions of the Entomological Society of London 4, 267-276.

Handling editor: Lyn Cook 